\title{
Who Feels It? Income Inequality, Relative Deprivation, and Financial Satisfaction in U.S. States, 1973-2012
}

\author{
Orestes P. Hastings * \\ pat.hastings@colostate. edu \\ Colorado State University \\ Department of Sociology
}

January 2019

Forthcoming in Research in Social Stratification and Mobility https://doi.org/10.1016/j.rssm.2019.01.004

\footnotetext{
*This paper has benefited from the helpful advice and comments of David Brady, Claude Fischer, Neil Fligstein, David Harding, Mike Hout, Hilary Hoynes, Lane Kenworthy, Vida Maralani, Christopher Muller, Daniel Schneider, Tim Smeeding, and the Berkeley Mathematical, Analytical, and Experimental Sociology working group. Previous versions were presented at the 2015 ISA RC28, 2016 SASE, and 2016 ASA conferences.
} 


\title{
Who Feels It? Income Inequality, Relative Deprivation, and Financial Satisfaction in U.S. States, 1973-2012
}

\begin{abstract}
Many accounts posit that as income inequality rises, individuals will be less satisfied with their own financial situation as they feel increasingly deprived relative to others - driving these individuals to spend more as they engage in positional competition and increasing their anxieties as position in the income distribution becomes ever more important. I examine if and for whom income inequality reduces financial satisfaction by analyzing the 1973-2012 General Social Surveys linked to state-level administrative data based on tax returns, the Census, and the American Community Survey. I find that higher state-level income inequality decreases financial satisfaction overall, and I further find that this effect is especially pronounced for those in the middle of the income distribution. Counterfactual simulations suggest rising income inequality explains a substantial portion of a four-decade decline in financial satisfaction.
\end{abstract}

Keywords: Income inequality; Relative deprivation; Financial satisfaction; Contextual effect 


\section{Introduction}

Income inequality in the United States has risen sharply over the past forty years. In 1973, the top $10 \%$ of earners made one-third of the national income, but by 2012 their income share was over one-half (Piketty and Saez 2003 [2015]). Over the same time period, the national Gini index in the United States rose from .47 to .64 (Frank 2014). ${ }^{1}$ Scholars, pundits, and public figures alike have raised alarm about this trend, suggesting high or rising income inequality leads to a variety of negative outcomes, but the empirical evidence has been far from definitive (Neckerman and Torche 2007; Van de Werfhorst and Salverda 2012; Moss et al. 2013; Atkinson and Bourguignon 2015; Kenworthy 2016). ${ }^{2}$

Many of the mechanisms proposed to explain why inequality could or should matter utilize the concept of relative deprivation (Merton and Rossi 1950; Davis 1959; Runciman 1966). That is, in modern, developed economies inequality does not deprive people of seemingly life-sustaining necessaries (e.g., food, shelter, basic health care), but ratherbecause it makes them less well-off relative to others above them-inequality restructures people's evaluations of their own financial well-being. More negative evaluations could then affect decisions about work, leisure, rest, debt, housing, policy preferences, family, and more.

Early scholarship defined relative deprivation as an objective measure of where one stood relative to others in terms of income (Yitzhaki 1979; Adjaye-Gbewonyo and Kawachi 2012). Yet the theories of why inequality matters depend not just on objective position, but on the extent to which one feels deprived. Income inequality may matter when it widens the gap between one's economic position and where one feels they "ought" to be based on what they see in others.

To see if income inequality affects these feelings, this paper examines the empirical relationship between state-level income inequality and financial satisfaction. The paper proceeds as follows: First, I elaborate on theories of relative deprivation and their link to financial satisfaction. Then, I explain why these may be affected by income inequality. I describe how the expected effects of income inequality may depend on one's position on the income distribution, but show that there are competing theories about which part of the distribution should be most affected by income inequality. Based on these theories, I develop a set of competing hypotheses that I test by analyzing the effect of the state-level Gini index on financial satisfaction using the 1973-2012 General Social Surveys linked to state-level data based on IRS tax returns, the decennial Census, and the American Community Survey.

Using models that account for time-invariant differences between states and that include a wide range of individual- and state-level controls, I find evidence that income inequality reduces financial satisfaction. Furthermore, I find that this effect of income inequality is most pronounced for those in the middle of the income distribution. I assess the robustness of these results to multiple measures of income inequality, various modeling approaches, and different contextual and individual covariates. Finally, I use a counterfactual simulation to

\footnotetext{
${ }^{1}$ Specifically, this is a pre-tax and transfer measure of inequality calculated from the Adjusted Gross Income (AGI) reported in IRS's Statistic of Income based on federal tax returns (Frank 2014). Alternative calculations from the CPS and Census Bureau show a similar rise, though the values differ because of how that income data is collected. The advantages and limitations of this data are discussed in both the Data and Methods and the Discussion and Conclusion sections of the paper.

${ }^{2}$ They may be talking about economic inequality, more generally. While different forms of economic inequality (e.g., income, wealth, or consumption inequality) are distinct from one another, in the U.S. context income inequality has been a driving factor of other types of economic inequality (Piketty 2014; Saez and Zucman 2016; Keister and Lee 2017).
} 
show that income inequality likely explains a substantial portion of a four-decade decline in financial satisfaction.

This paper contributes to the sociological study of income inequality by focusing on feelings of relative deprivation and financial satisfaction-factors scholars have suggested should be a key mediator between income inequality and critical social problems, but that have rarely been examined directly. It makes an empirical contribution through a rigorous analysis of the effects across the income distribution of over four decades of growing income inequality in U.S. states.

\section{Relative Deprivation and Financial Satisfaction}

Scholars have studied financial satisfaction - that is, an individual's subjective evaluation of their financial situation - as both a "sub-construct" or domain of subjective well-being and life satisfaction (e.g., Van Praag et al. 2003; DePianto 2011; Diener and Biswas-Diener 2002) and as an important component of perceived economic standing (e.g., Kalleberg and Marsden 2012; Joo and Grable 2004). Unsurprisingly, there is a robust association across a number of contexts between the income of an individual or household and their level of financial satisfaction (e.g., DePianto 2011; Diener and Oishi 2000; Easterlin 2006). Additional work has shown financial satisfaction to be a mediator between income and overall or "global" life satisfaction (see review by Diener and Biswas-Diener 2002).

Yet research also suggests that the ability to derive satisfaction from income is highly context dependent-not only does it matter what one makes, but also how that stands in relation to others. One of the most concise accounts of this is articulated in the Easterlin Paradox, which notes that although individuals with more income report being happier, an increase in average income over time for a country does not translate into greater happiness overall for that country (Easterlin 1973). At present, some scholars debate whether average income really lacks any explanatory power on happiness (see Stevenson and Wolfers 2008; 2013, and responses by Easterlin et al. 2010). Some suggest that absolute income may indeed have some positive effects, but that in the U.S. the efforts to obtain that incomenamely, working more hours and increasing the number of dual-earning households - have had counteracting negative effects (Fischer 2008; Schnittker 2008). Still, there remains ample evidence that relative income is an important determinant of financial - and ultimatelyoverall satisfaction.

In fact, social comparisons of income and other material goods have been foundational to the social sciences. In The Theory of the Leisure Class, Veblen ([1899] 1963) described how social status is demonstrated and reified through visible forms of consumption that others can see and compare themselves against. Duesenberry's (1949) relative income hypothesis stated that people's consumption and savings behaviors depend heavily on income in relation to others. And Marx (1847 [1972]) illustrated the idea when writing that, "A house may be large or small; as long as the neighboring houses are likewise small, it satisfies all social requirement for a residence. But let there arise next to the little house a palace, and the little house shrinks to a hut." (p. 33)

These early ideas were formalized in the theory of "relative deprivation" which assumes that the comparisons individuals make with others who are more advantaged can cause them to feel deprived (Merton and Rossi 1950; Davis 1959; Runciman 1966). Rather than lacking in absolute terms such as being without adequate shelter, clothing, or food - factors that are more relevant to conceptions of poverty (Iceland 2012)-relative deprivation focuses 
on lacking the goods or resources that one desires or feels necessary to fully participate in society (Runciman 1966; Adjaye-Gbewonyo and Kawachi 2012).

Building on this understanding, financial satisfaction is clearly related to this theoretical conception of relative deprivation. In Falling Behind, Frank (2007) emphasizes that such comparisons that would lower financial satisfaction need not be made out of envy. Rather, it is "fundamentally about the link between context and evaluation" (p. $x x$ ). Wants and felt needs are shaped by one's context - the greater the standards, the more income necessary to be satisfied, and the easier it becomes to be dissatisfied with the income one actually has. In particular, the standards are mostly to increase for those things that can become sources of evaluation are aptly described as "positional goods" (Hirsch 1977). Yet the resulting potential drawbacks from this competition are two-fold: not only does it require increasingly more income to acquire them, but, in turn households may also be prompted to reduce their consumption of so-called "non-positional goods" such as vacations, leisure time, and sleep.

\section{The Effect of Income Inequality}

Does rising inequality increase these feelings of relative deprivation and decrease financial satisfaction? As income inequality grows, so does the distance between those at different parts of the income distribution, potentially resulting in greater contrasts and more opportunities for negative comparisons. This could happen in two ways. First, as noted above, as inequality increases, so too may inequality in the consumption of positional goods (Frank 2007). There is ongoing scholarly debate on the extent to which overall consumption inequality (spending in all areas) has (or has not) mirrored rising income inequality. Recent studies from the Consumer Expenditure Survey (CEX) have reached mixed conclusions: some studies arguing consumption inequality has risen substantially (Aguiar and Bils 2015; Attanasio et al. 2015) while others claiming the increase has been minimal (Krueger and Perri 2006; Meyer and Sullivan 2017) Complicating the matter is that the CEX has likely experienced greater measurement error in recent years (Meyer et al. 2015) and, more generally, consumption data measures spending within categories, rather than the quality or quantity of the items purchased (see also Fisher et al. 2013; Attanasio and Pistaferri 2016). However, studies examining specific positional goods such as neigborhoods (Frank 2007; Fligstein et al. 2017; Goldstein and Hastings 2018), cars (Bricker et al. 2014), and luxury goods (Walasek and Brown 2015; 2016) find that the focus on them seems to increase when and where income inequality is greater. Second, people may to some extent compare incomes directly. While Americans have limited knowledge about what others make, some salaries and wages are public (e.g., many public sector and unionized workplaces, see Rosenfeld 2017) and others can be approximated through hearsay, personal experience, and the news (McCall 2013). Even though people have limited understandings of the income distribution (Hauser and Norton 2017), even imperfect information may credibly inform people's perceptions of their position relative to others.

Yet, most previously attempts to operationalize "relative deprivation" define it as a function of one's position in the income distribution, regardless of one's perception of that position. This is exemplified in Yitzhaki's (1979) definition of relative deprivation as the average of the income differences between a person and everyone else in the population who has a higher income than them. Yitzhaki's measure and variants of it remain the standard (see Adjaye-Gbewonyo and Kawachi 2012), but these metrics mechanically link relative deprivation and income inequality. For any population, the average level of Yitzhaki's 
relative deprivation is the mean income multiplied by the Gini index, meaning that - net of mean income - any society with more income inequality will have more relative deprivation (Evans et al. 2004). But while rising inequality means people are objectively more deprived relative to others, existing work has not demonstrated to what extent people may or may not feel that deprivation and be less financially satisfied as a result.

Scholars have described two explanations of how income inequality could reduce financial satisfaction. One view focuses on how relative deprivation drives others to overspend to "keep up with the Joneses" or to be dissatisfied when they do not keep up. For example, Frank (2007) argues inequality arises when the growth of top incomes sets off a chain of local comparisons that cascade all the way down to low income earners. He describes this as the increasing "cost of adequate" which leads to dissatisfaction, stress, and other adverse outcomes.

Another view focuses on how relative deprivation may result in anxiety over one's place in the social hierarchy of status and prestige. As inequality increases, one's position becomes ever more crucial. Scholars have argued that this leads to status anxiety and increases levels of stress, which then results in a number of negative consequences that are psychological, physical, and social. Among the leading proponents of this position are Wilkinson and Pickett, who popularized this argument in The Spirit Level (2010). They use both cross-national and between-state comparisons to argue that the additional status anxiety generated by income inequality can explain associations between income inequality and loss of community life; poor mental and physical health; higher drug use, obesity, mortality, teen births, and crime; and lower educational performance (see also Wilkinson and Pickett 2009).

But Wilkinson and Pickett do not measure feelings of relative deprivation or financial satisfaction. Rather, they argue that the evidence supports their argument because the outcomes associated with income inequality have a "status gradient." That is, health and social problems that are typically more common lower down the income distribution are also more common in unequal contexts, while problems without a status gradient are less associated with inequality. From this they infer that income inequality has effects through the relative differences between individuals. While "status" is presented broadly, implicit in these arguments is an increasing concern with one's income and where it stands in relation together.

Both arguments suggest that rising income inequality should be a cause of less financial satisfaction (to be clear, neither articulation requires that people know the level of inequality - only that they experience it and navigate life through it), something this paper tests empirically. Although no study does this directly, two studies use similar arguments to test related outcomes. One study examined the effect of income inequality on status anxiety in a cross-sectional study of European countries (Layte and Whelan 2014). Respondents were asked the extent to which they agreed with the statement "Some people look down on me because of my job situation or income." On average, individuals in more unequal countries were more likely to agree. In contrast, scholars in another study of European countries analyzed questions about status seeking and found that people reported being less concerned about status seeking in more unequal contexts (Paskov et al. 2017). They suggest as inequality rises, people may "give up" on their efforts to keep up. Comparable studies in the U.S. context do not yet exist.

The above discussion suggests there may be, on average, a negative effect of income inequality on financial satisfaction, leading to the following ceteris paribus hypothesis:

Hypothesis 1: Income inequality is associated with lower financial satisfaction. 


\section{Heterogenous Effects}

Many studies - both theoretically and empirically — have focused on the overall (i.e., populationaverage) effect of income inequality. Practically speaking, some of this is because much of the work on the effects of income inequality has been conducted using outcomes at the aggregate level, rather than at the individual level. Although sometimes adequate data exist only at the aggregate level, an ecological fallacy can occur when inferring individual-level processes from aggregate data (Evans et al. 2004). Moreoever, aggregate data can, at best, only establish population-level effects. This makes it impossible to distinguish how income inequality may affect people differently who are at different places on the income distribution.

As noted above, prior scholarship has clearly established that income itself is positively associated with financial satisfaction. There are also compelling arguments that the effect of inequality on financial satisfaction should vary across the income distribution, but the existing theories - all of which suggested an average decline in financial satisfaction-yield conflicting expectations about how this effect would (or would not) vary across the income distribution.

\subsection{Effects smallest at top; largest at bottom}

Relative deprivation theory emphasizes the negative comparisons that people make with those who are more advantaged. The further down one is on the income distribution, the more opportunities one has to make negative comparisons. Conversely, the higher up one is, the fewer negative comparisons there are to make. By definition, greater income inequality means a stretching of the income distribution, and thus, the relative deprivation of everyone not at the top increases.

We know there is an association between relative income and financial satisfaction, so we expect that, ceteris paribus, the effect of inequality should be smallest at the top of the income distribution and largest at the bottom of the income distribution. Layte and Whelan (2014) similarly proposed that the negative effect of individual income rank on status anxiety would be exacerbated (i.e., positively moderated) by increasing income inequality, but they did not find support for this hypothesis. However, financial dissatisfaction resulting from feelings of relative deprivation is a different concept than status anxiety. For example, while it is plausible that feelings of relative deprivation may induce status anxiety, feeling deprived may also lead to overspending and/or financial dissatisfaction even among those who do not feel negatively judged because of their income (or lack thereof).

Hypothesis 2a: The association between income inequality and financial satisfaction is the least negative for those at the top of the income distribution and increases for those lower on the income distribution (i.e., there is a steeper income gradient between individual income and financial satisfaction when inequality is higher).

Relative deprivation theory typically assumes individuals mostly ignore those who are less advantaged than them. But an extension of this is "Relative Gratification Theory" which proposes that comparisons with those who earn less will make individuals feel better (Davis 1959; Evans et al. 2004). If people compare themselves to others both above and below them, then not only would we expect a steeper gradient between income and financial satisfaction, but we may find a positive effect of income inequality for those near the top of the income distribution. 
Hypothesis 2b: The association of income inequality and financial satisfaction is positive for those near the top of the income distribution.

\subsection{Effects largest in the middle}

In contrast, because income inequality in the U.S. has been primarily driven by the growth of top incomes (Piketty and Saez 2003 [2015]), those in the middle may be more sensitive to these gains, while those at the bottom (correctly) may not perceive those in the middle pulling away so much. This makes sense if what occurs is not comparisons to those throughout the entire income distribution, but local comparisons to those just above. This is precisely Frank's (2007) account: for the middle class, the losses from the "positional arms race" have been made worse by rising inequality, and through a chain of local comparisons, they spend more while diverting resources away from non-positional goods, causing large welfare losses. ${ }^{3}$

A variant of this explanation has a more cultural emphasis. Those near the middle may experience the greatest gap between their aspirations and economic reality. Studies suggest that the standards are increasing for the so-called "middle class" lifestyle in the U.S.- which often includes owning a (larger) house and (nicer) car and having a good job, some modest savings, and enough money to pay for one's children's college education(s) are increasing, meaning those in the middle more often do not have the means to pay for these them (Schor 1998; Dwyer 2009). Rising income inequality is likely a driver behind these elevated standards (Frank 2007; Walasek and Brown 2015; Fligstein et al. 2017). As a result, those in the middle may be the most discontent as they fail to achieve these goals or take on considerable debt to meet these aspirations (Fligstein and Goldstein 2015). In contrast, higher earning households may be able to meet more of these "middle-class" goals, while those at the bottom may recognize that these things are out of reach.

Hypothesis 3: The association of income inequality and financial satisfaction is most negative in the middle.

It is possible, of course, that the association between income inequality and financial satisfaction is similar across the income distribution. If inequality increases status anxiety by making everyone feel insecure about their position (regardless of whether they are high or low), then these effects should be felt everywhere. This would be consistent with the findings mentioned above that although income inequality increased self-reported status anxiety, this was not moderated by income (Layte and Whelan 2014), but there would also be no variation if there was no substantive effect of income inequality on financial satisfaction.

\section{$5 \quad$ Data and Methods}

\subsection{General Social Survey}

The individual-level data come from the nationally-representative General Social Survey (GSS) which has been conducted annually or biannually since 1972 with response rates greater than 70\% (Smith et al. 2013). Unlike other long-running nationally-representative

\footnotetext{
${ }^{3}$ Hence Frank's (2007) book's unsubtle subtitle: How Rising Inequality Harms the Middle Class.
} 
surveys, the GSS asks a large number of questions about attitudes, including financial satisfaction. I obtained the restricted-access GSS geographic identification file that contains state identifiers for every survey year beginning with 1973 and matched each respondent to a variety of state-level measures described below. ${ }^{4}$

\subsubsection{Outcomes}

Financial satisfaction is measured with the question "So far as you and your family are concerned, would you say that you are pretty well satisfied with your present financial situation, more or less satisfied, or not satisfied at all?" (codebook item: satfin). In the main analysis I present this as a continuous variable, but I also found substantively identical results when using ordered logistic regression and multinomial logistic regression.

Figure 1 shows how this variable has changed over time. There has been an overall decline of about .15 on the 3 point scale (abut 0.2 standard deviations). Looking at the change in each response category, it is evident that this is driven by a decline in the proportion of respondents who report being "satisfied" (from 32\% to 26\%) and an increase in "not at all satisfied" (from $24 \%$ to $29 \%$ ), while the proportion who are "more or less satisfied" has remained about the same (about $45 \%$ ).

Figure 1: Lowess Plots of Financial Satisfaction from 1973 to 2012 for each Response Category and the Overall Mean (Source: General Social Survey)

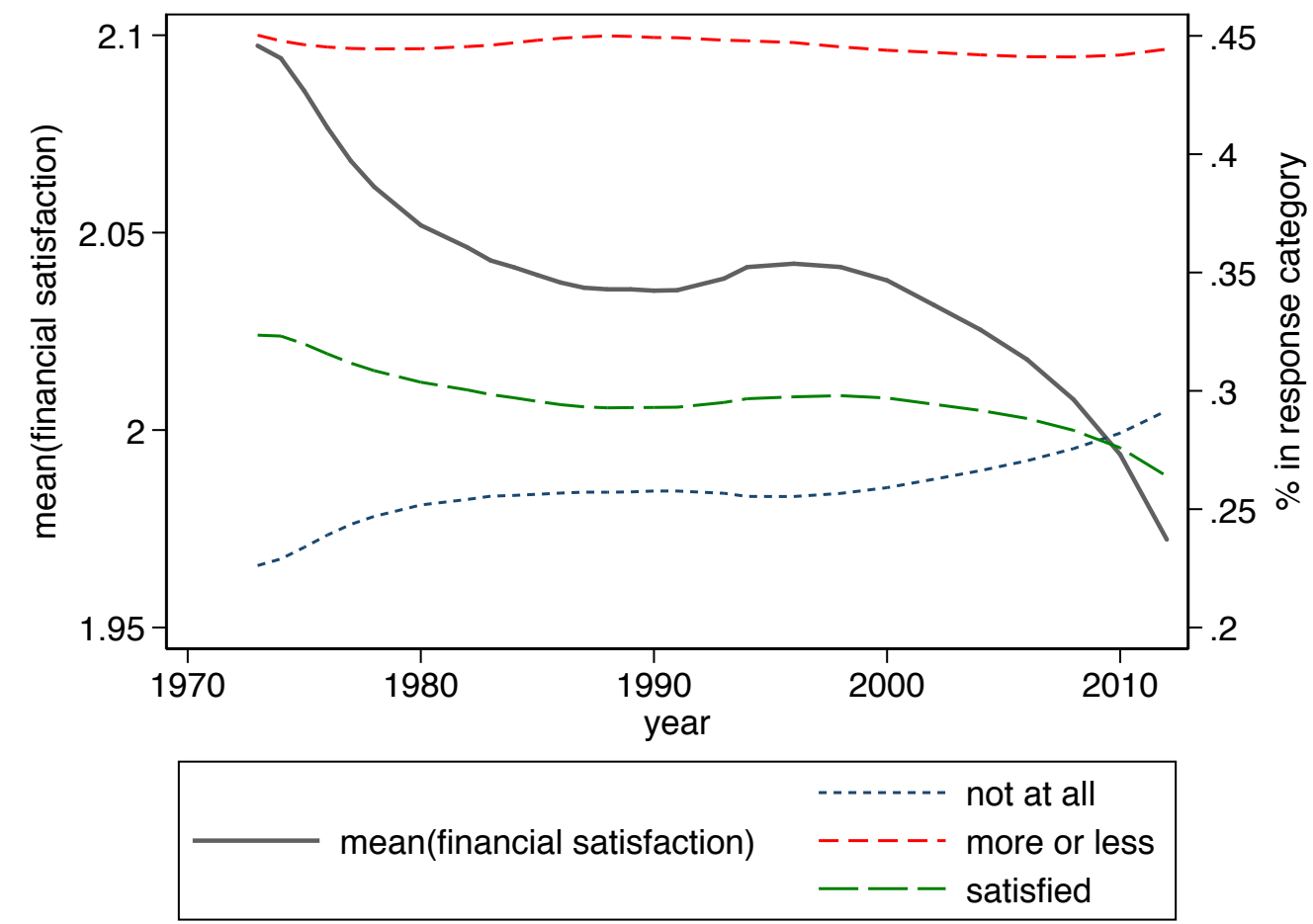

\footnotetext{
${ }^{4}$ Data from the GSS, Census, and ACS are available from the respective websites of each. The inequality data based on IRS tax returns are available at http://www.shsu.edu/ eco_mwf/inequality.html. However, the GSS state-level identifiers can only be obtained through special contractual arrangements with NORC: http://gss.norc.org/documents/other/ ObtainingGSSSensitiveDataFiles.pdf
} 


\subsubsection{Individual-level Independent Variables}

Income was measured by asking respondents to place their household's income into an income bin. The bins have changed over time, but the GSS provides a harmonized "best estimate" by assigning each respondent the midpoint of their income bin, except for the open-ended top income bin where incomes were assigned using a Pareto curve (Ligon [1989] 1994; Hout 2004). I divide the respondents into income quintiles by year. I found similar results when using 7 and 10 groups rather than 5, and when dividing the total sample into quintiles, instead of for each year. I also found similar results by dividing each household's income by their state-year median and then separating this state-year adjusted income into quintiles by year, and I also found similar results in models that controlled for income alongside the income bins.

To control for characteristics that might bias the relationship between income inequality and the dependent variables, I include measures for the respondent's sex, age, age squared, race/ethnicity (non-Hispanic white, non-Hispanic black, other non-Hispanic, and Hispanic), years of education (using highest degree earned made no change to the main findings), marital status (married, widowed, divorced, separated, or never married), number of children in the household, number of adults in the household, work status (full-time, part-time, temporarily not working, unemployed, retired, in school, keeping house, other), political party affiliation (Republican, Democrat, independent/other), religious service attendance (from $0=$ never attend to $8=$ attend more than once a week), and type of area of residence (urban, suburban, or rural). The GSS did not measure Hispanic or Latino ethnicity until 2000, so for observations before that year I use country of ancestral origin. This correlates extremely well with self-identified Hispanic from 2000 onward (the tetrachoric correlation is .99) and has been used in previous research on race and ethnicity (Hout and Goldstein 1994).

\subsection{Area Level Data}

\subsubsection{Income Inequality}

While the outcomes are at the individual level, inequality itself is a population-level characteristic. This paper argues that financial satisfaction may be shaped by area-level inequality, but it is not readily apparent what the appropriate unit of aggregation is to measure income inequality. I focus on U.S. states for both theoretical and pragmatic reasons. First, although some studies measure inequality at the local level, scholars have argued that relative deprivation should operate at a larger level such as the state (Wilkinson and Pickett 2009). This may seem counterintuitive if one expects the effects to result directly from face-to-face encounters with others, but the processes described above also depend heavily on the extent of the separation between those on different parts of the income distribution which may not be captured when looking at the inequality of smaller areas.

Second, states have been used extensively in prior studies of income inequality effects and evidence suggests there are net state-level income inequality associations for some of the outcomes that could result via financial dissatisfaction. Third, policy interventions are frequently applied at the state level, so understanding whether psychosocial effects appear at the same level may be especially useful for those interested in the potential policy implications of these analyses.

Fourth, unlike for sub-state areas, excellent annual state-level income inequality data 
are available (described below). Fifth, unlike counties, MSAs, and other sub-state areas, states have maintained consistent boundaries over time. Finally, sixth, the GSS geo-coded data only has location identifiers below the state beginning in 1993, making it impossible to examine the effect of inequality during the first 20 years of the survey for smaller levels. Excluding these respondents would dramatically reduce the sample and omit about half the income inequality growth between 1973-2012.

My income inequality measure is the state-level Gini index. The Gini is the average distance between all pairs of proportional income in the population, ranging from 0 (if everyone had the same income) to 1 (if one household had all the income). The Gini assesses inequality across the entire income distribution and is the most common inequality measure in previous research.

The Gini is calculated and made available by Frank (2014) from data published in the IRS's Statistics of Income. Alternative state-level data sources of income inequality come from the Current Population Survey (CPS) and the Census Bureau (decennial Census until 2000 and American Community Survey (ACS) afterwards) (Stone et al. 2016), but the IRS-based data provides a number of advantages including being based all returns rather than a smaller sample, being available annually, relying on reports where respondents are penalized for income reporting errors (Akhand and Liu 2002; Hümbelin and Farys 2016), and being subject to less top-coding (Richard et al. 2009). IRS-based data does risk censoring households whose income is below the threshold for mandatory tax filing, but these households may still file taxes to benefit from tax credits or receive a tax refund. ${ }^{5}$

\footnotetext{
${ }^{5}$ See Hastings (2018) for additional discussion of differences between the data sources. All of these data series are based on pre-tax and transfer income. Although post-tax and transfer income would be ideal since it better measures disposable income, no such data series exists at the state level. In cross-national work, using pre-tax and transfer income is especially problematic (Ferreira et al. 2015; Guillaud et al. 2017), but this is much less the case in state-level work for two reasons. First, there is much less variation between states in their taxes and transfers as compared to nations. Second, the models employ state fixed effects, so it is only change over time that matters (i.e., average difference between high tax-and-transfer states and low tax-and-transfer states are netted out).
} 
Figure 2: 90th, 50th, and 10th Percentiles of the State Gini Index of Income Inequality, 1973-2012 (Data source: Frank 2014)

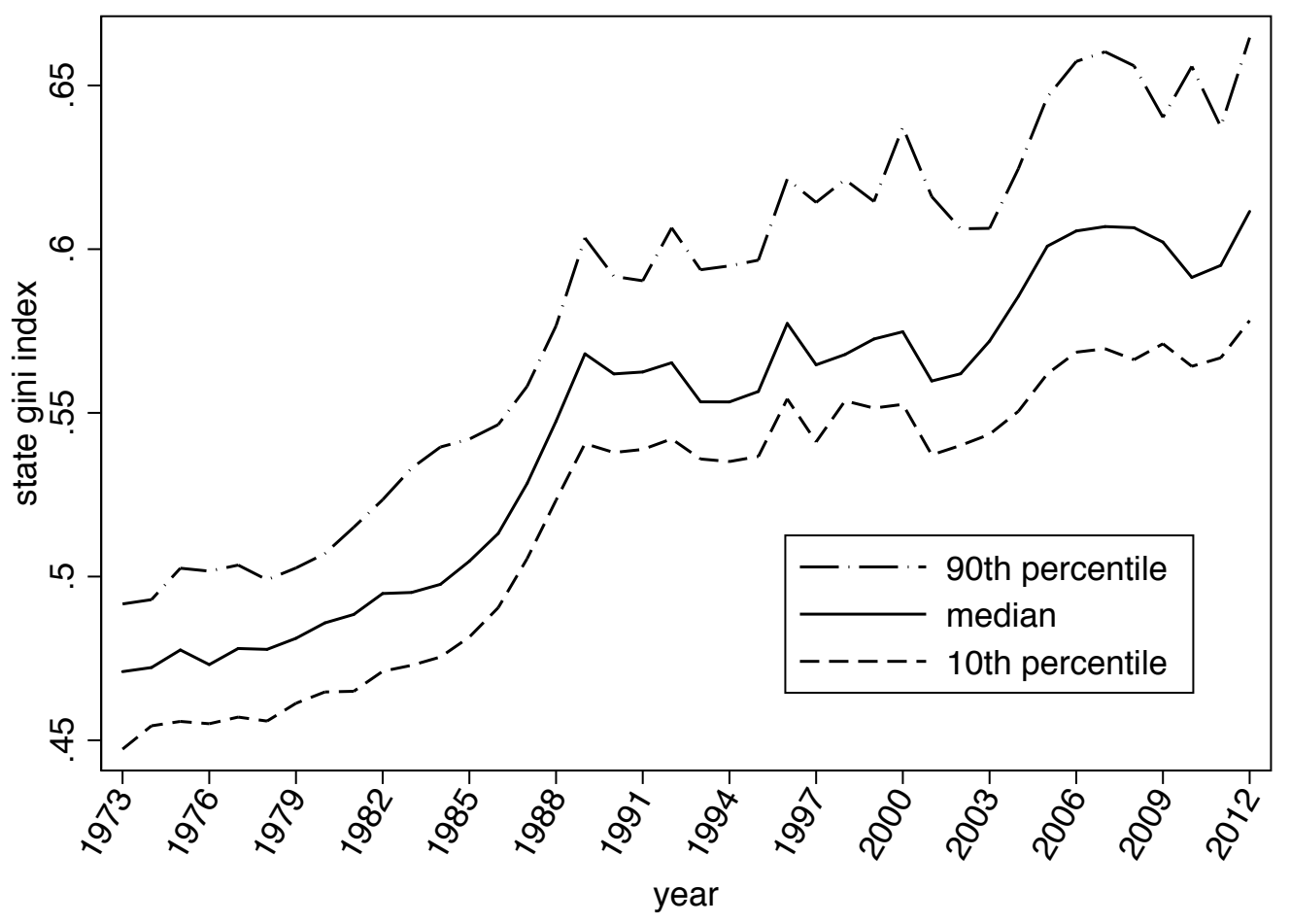

Some recent research has focused on top income shares (Frank 2014; Piketty and Saez 2003 [2015]), but the hypotheses tested here would seem to be sensitive to changes in income inequality across the entire distribution, so I focus on a measure that is similarly sensitive to these changes. Figure 2 shows the Gini index across states during the analysis period. Two trends are notable. First, consistent with other accounts of income inequality, inequality grew considerably over the period of study. In fact, the Gini of the least equal state in 1973 (.50 in the District of Columbia) was lower than in the most equal state in 2012 (.55 in West Virginia). Second, the gap between the $10^{\text {th }}$ and $90^{\text {th }}$ percentiles is nearly twice as large in 2012 as 1973, meaning that inequality grew substantially more in some states than others.

\subsubsection{Other Area Level Data}

I control for state-level median household income (logged) which is often used as a measure of standard of living and is less sensitive than mean income to measurement errors of high income. I control for changing racial composition with the percent black in each stateyear. Deaton and Lubotsky (2003) argue that race is a confounder of income inequality effects, showing in one analysis that the inclusion of the proportion black explains away a relationship between state-level income inequality and mortality. This study has since been challenged in several respects (e.g., Ash and Robinson 2009), but Pickett and Wilkinson (2015) also question whether such explanations are even theoretically appropriate, suggesting that "ethnic differences attract more attention and seem more important not only when they become markers of social status differences but also when greater inequality makes social status differentiation more powerful, increasing the importance of 'downward' social 
prejudices whether by class or ethnicity." (p. 7). Thus, controlling for race presents a more conservative estimate. Hispanic or Latino ethnicity was not consistently recorded in the census until 1980 and is not included, but I control for the percent foreign born in each state-year. Finally, I control for state population density (logged) to account for population shifts and growth. These measures come from the decennial Census for 1970-2000 (except that households reported the previous year's income, so median income is measured for 1969, 1979, 1989, and 1999) and the annual ACS for 2005-2012. I linearly interpolated between data points to create annual measures, except for percent black, for which model-based annual estimates are provided by the Census Bureau. Descriptives of all individual- and state-level measures are presented in the Appendix.

\subsection{Analytical Strategy}

The analytic approach is to conduct an individual-level analysis of financial satisfaction. Though much prior work on the effects of income inequality has been conducted at the aggregate level, this research is vulnerable to an ecological fallacy. Moreover, aggregate-level analysis can only establish population-level effects, making it impossible to distinguish how income inequality may affect people differently across the income distribution, something this paper also examines.

I estimate a linear regression model with state fixed effects and time-varying controls. Many studies of income inequality employ cross-sectional comparisons across countries or states at a single point in time, but this design risks confounding the effects of income inequality with unobserved characteristics of areas that shape both income inequality and the outcomes being studied. Panel data can exploit within-area temporal variation in income inequality and net out unobserved time-invariant characteristics, as I do with the inclusion of state fixed effects. In all, I analyze 51,699 observations in 1,063 state-years.

Formally, consider observation $i$ in state $s$ collected in year $t$. The regression equation (with bolded terms indicating vectors) is,

$$
\begin{aligned}
\text { Satisfaction }_{\text {ist }}= & \beta_{0}+\beta_{1} \text { Gini }_{\text {st }}+\boldsymbol{\beta}_{\mathbf{2}} \text { Income }_{\boldsymbol{i s t}} \\
& +\left[\boldsymbol{\beta}_{\mathbf{3}}\left(\text { Gini }_{\text {st }} \times \text { Income }_{\boldsymbol{i s t}}\right)\right] \\
& +\boldsymbol{\beta}_{\mathbf{4}} \text { Controls }+\boldsymbol{\mu}_{\boldsymbol{s}}+\epsilon_{i s t}
\end{aligned}
$$

where Satisfaction ist $_{\text {is }}$ the respondent's reported financial satisfaction, Gini $_{\text {st }}$ is the statelevel inequality measure, Income $_{\boldsymbol{i s t}}$ is a vector of the five indicator variables for each income quintile, Controls is a vector of the individual and state-level controls, $\boldsymbol{\mu}_{\boldsymbol{s}}$ specifies a full set of state indicators (i.e., fixed effects), and $\epsilon_{i s t}$ is the idiosyncratic error. I place the interaction of the Gini index and the income quintiles in brackets to show that I estimate this model both with and without these terms. Without these terms, $\beta_{1}$ represents the overall effect of the Gini on financial satisfaction. By including the interaction terms, I can assess how the effects vary across the income distribution. In all models I employ the sampling weights provided by the GSS and adjust the standard errors for clustering within states. ${ }^{6}$

\footnotetext{
${ }^{6}$ This clustering accounts for individuals appearing more than once because of the panel structure of the GSS beginning in 2006. I cluster at the highest level (states). The clustered variance estimator accommodates an arbitrary variance-covariance matrix within each cluster, so it is robust to the presence of lower levels of clustering (Cameron and Miller 2011). This approach treats individuals that move between states as independent observations, but excluding repeat observations from
} 
I do not include year fixed effects in the main models, as adding them nets out the average level of inequality for each year and forces the estimate to be based on changes in income inequality within states net of the overall growth of income inequality across states. Inequality grew in all states, as shown in Figure 2. As a result, this approach may be overly conservative, netting out much of the variation in income inequality that we are interested in understanding. However, I present models with year fixed effects as a robustness check (Appendix Table A4) and show these produce results with a similar magnitude and direction but have much larger standard errors.

Many studies of income inequality prefer to specify a multilevel model (i.e., mixed or hierarchical linear models) to understand the effects of inequality. In the multilevel approach, $\beta_{1}$ is estimated from variation both between and within states and years and "borrows strength" across groups (i.e., state-years) when they are small (Gelman and Hill 2007). As a result, this model is more efficient (i.e., yields smaller standard errors) but requires the untestable "random effects" assumption - in this case that any unobserved characteristics of the states that influence the outcomes are not correlated with any of the individual- or state-level measures that are included with the model. These models also account in their standard errors for the clustering of observations within shared contexts without needing post-hoc clustering adjustments that are done in the fixed effects regression models (RabeHesketh and Skrondal 2012). Despite the differences, I find substantively the same results with the random effects approach as compared to the fixed effects approach above (Appendix Table A5)

Because the outcomes measure the attitude of the respondent at the moment of completing the survey, I use income inequality for the same year. It is possible that respondents take some time to "update" their mental understanding of how they compare to those around them, so for robustness I also consider the models with a lagged Gini.

I consider several other robustness specifications. I reestimate the models using alternative sets of control variables (no controls, individual controls only, state controls only). I consider the effect of outliers by removing the most and least unequal state observed in each year. And I reestimate the preferred models without survey weights. The results of the robustness checks are discussed in a section following the results from the preferred model.

After estimating the effect of inequality, I then examine the overall time trend in financial satisfaction and I present a counterfactual simulation of how financial satisfaction might have changed over time had inequality not risen. As noted in Figure 1, financial satisfaction has declined over time. How much of this can be attributed to changes in inequality? We know inequality rose over the same time period, as shown in Figure 2, but, of course, many things changed in the U.S. besides inequality, which is precisely the motivation for doing the multivariate analysis in the first place.

The appropriate counterfactual is not "no change" in financial satisfaction over time, but rather the estimation of how financial satisfaction would have changed had inequality remained constant. To estimate this, I take the coefficients from the final model and make two predictions for each observation. First, I predict each respondent's financial satisfaction using all of the observed values for all individual- and state-level variables (this is the traditional $\hat{y}$ of a regression model). Second, I predict each respondent's financial satisfaction using the observed values except replacing the state Gini with its mean level in 1973. I

movers does not alter the main results. As would be expected, removing clustering entirely generated smaller standard errors and smaller p-values for the coefficients of interest. Results available upon request. 
compare these results visually using locally weighted regression (lowess) plots (bandwidth $=.8$ ) employing the sampling weights provided by the GSS, both for the full sample and by income quintile, in order to evaluate income inequality's long-term effect on financial satisfaction.

\section{Results}

\subsection{Main Effect}

Table 1 presents the main results for the effect of income inequality on financial satisfaction (full results with all coefficients are in Appendix Table A3). The baseline income group is the middle income quintile, which includes the median earner. Model 1 shows the main effect of inequality (Hypothesis 1) while Model 2 adds interactions between inequality and the respondent's income quintile, in order to see how the effect varies across the income distribution (Hypotheses 2a, 2b, and 3).

Table 1: Coefficients from Models of Financial Satisfaction

\begin{tabular}{|c|c|c|c|c|}
\hline & (1) & & (2) & \\
\hline State Gini & $-0.30^{*}$ & $(0.13)$ & $-0.54^{* *}$ & $(0.20)$ \\
\hline Q1 (bottom) & $-0.30^{* * *}$ & $(0.014)$ & $-0.30^{* * *}$ & $(0.014)$ \\
\hline Q2 & $-0.16^{* * *}$ & $(0.0091)$ & $-0.16^{* * *}$ & $(0.0091)$ \\
\hline Q3 & ref. & & ref. & \\
\hline Q4 & $0.16^{* * *}$ & $(0.012)$ & $0.16^{* * *}$ & $(0.011)$ \\
\hline Q5 (top) & $0.41^{* * *}$ & $(0.016)$ & $0.41^{* * *}$ & $(0.015)$ \\
\hline Q1 (bottom) $\times$ Gini & & & $0.38^{*}$ & $(0.17)$ \\
\hline Q2 × Gini & & & 0.0032 & $(0.13)$ \\
\hline Q3 $\times$ Gini & & & ref. & \\
\hline Q4 × Gini & & & 0.27 & $(0.21)$ \\
\hline Q5 (top) $\times$ Gini & & & $0.55^{*}$ & $(0.25)$ \\
\hline State poverty rate & $-0.011^{* * *}$ & $(0.0031)$ & $-0.011^{* * *}$ & $(0.0031)$ \\
\hline State median income (logged) & 0.14 & $(0.092)$ & 0.14 & $(0.092)$ \\
\hline Individual Controls & Yes & & Yes & \\
\hline State Time-varying Controls & Yes & & Yes & \\
\hline State Fixed Effects & Yes & & Yes & \\
\hline Observations & 51699 & & 51699 & \\
\hline
\end{tabular}

Standard errors in parentheses

${ }^{*} p<.05,{ }^{* *} p<.01,{ }^{* * *} p<.001$

Notes: The middle income quintile (Q3) is the baseline category. Each model uses sampling weights and the standard errors are adjusted for clustering within states. Full models with all coefficients are in the Appendix.

The overall effect of income inequality is negative and significant. In Model 1 , a 0.1 increase in the Gini (about 1.5 standard deviations) is associated with a $0.03(\approx 0.04$ standard 
deviation) decrease in financial satisfaction. To help understand these effects, I also report the coefficients for the state poverty rate and the logged state median income. Poverty also has a significant negative effect. For example, in model 1 a 0.1 increase in the Gini has about the same negative effect on financial satisfaction as a $\left(-0.30^{*} 0.1 /-0.011=\right) 2.7$ percentage point increase in the state poverty rate. State median income has a non-significant effect on financial satisfaction, which is consistent with the notion that relative - rather than absolute - income is what is more important for financial satisfaction. Taking the point estimates at face value, in Model 1 a 0.1 increase in the Gini has approximately the same effect size as a $20 \%$ decrease in state median income. ${ }^{7}$

These back-of-the-envelope coefficient comparisons should probably be interpreted cautiously, as changes to the poverty rate or median income are likely to change inequality as well, but they provide some evidence that these effects of inequality are indeed quite meaningful. Yet another way of sizing these effects is to consider the substantive implications from an over time perspective. Further below I also consider what portion of the overall change over time in the outcome could be explained by rising income inequality based on these models.

These models also show that the coefficients for the income groups are negative for quintiles below the middle quintile and positive for quintiles greater than the middle quintile. This is not surprising since this captures the effects of absolute income and the dimension of financial satisfaction that is about income rank, whereas the Gini captures the effect of a greater distance between ranks. Next, I consider how the Gini may have different effects depending on one's rank.

\subsection{Heterogenous Effects by Income}

Model 2 of Table 1 shows how the effect of income inequality varies across the income distribution. Here, the coefficient for the Gini represents the effect of income inequality for the middle income quintile. It is still negative, and it is greater in magnitude than in Model $1(\beta=-.54, \mathrm{p}<.01)$. The coefficients for the interaction term between the Gini and the 2nd and 4th income quintiles are not significant, but interaction coefficients for the highest and lowest income groups are both positive and significant. From this model, it appears the effect of income inequality is least negative for those at the top and bottom of the income distribution and is most negative for those in the middle (especially the second and third income quintiles).

To visualize these results, Figure 3 shows the predicted values of financial satisfaction for each income group in contexts of high and low income inequality while setting all of the remaining covariates to their mean values. The high inequality line shows the prediction when income inequality is at the level of the 90th percentile in the sample (Gini $=.64$ ), while the low inequality line shows the prediction for inequality at the level of the 10th percentile $($ Gini $=.47)$. Another way to think of these levels is that the "low inequality" value is about the median level of state inequality in 1973, while the "high inequality" value is about the

\footnotetext{
${ }^{7}$ State median income is logged, so the percent change will have the same effect on the outcome, regardless of the baseline income. Finding the comparable percent change to the effect of a 0.1 increase in the Gini requires solving

$$
\beta_{\log (\text { median income })} * \log (1+x)=0.1 * \beta_{\text {gini }}
$$
}

for $x$. 
median level of state inequality in 2012 .

Figure 3: Predicted Values of Financial Satisfaction by Income Group in Contexts of High and Low Income Inequality (from Model 2 of Table 1). Error bars show 95\% confidence intervals.

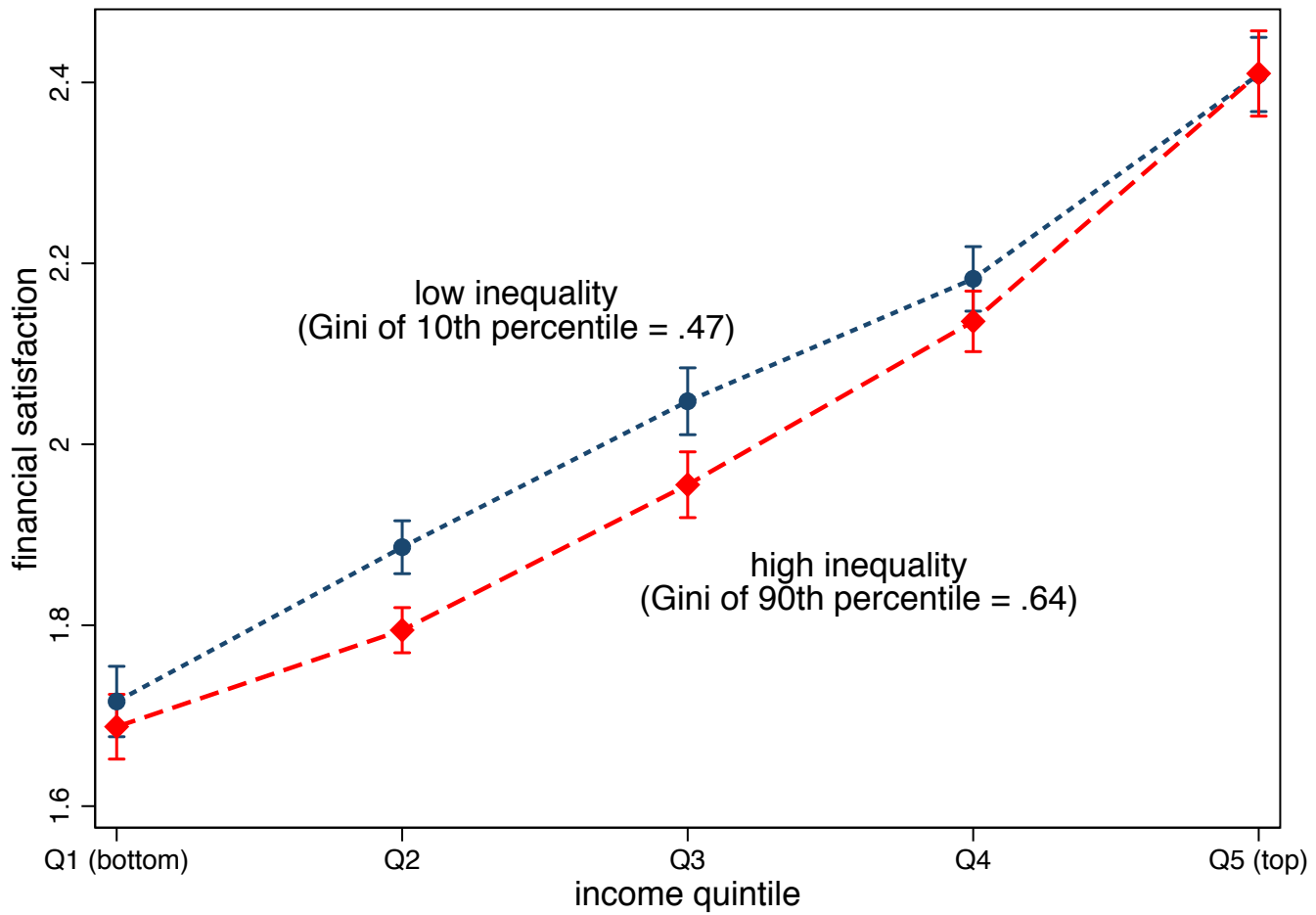

Figure 3 clearly illustrates that income inequality is negatively associated with financial satisfaction because the low inequality line is above the high inequality line. The gap is largest for the second and third income quintiles, and smallest at the top and bottom of the income distribution. For some perspective, the gap between high and low income inequality for the middle income quintile is slightly more than half the effect of moving from the middle quintile to one quintile above or below. Even if this is (debatably) not a large effect, it is important to note that changes in income inequality affect the entire population, whereas income changes for a single household affect only that household.

These findings show that there is substantial variation across the income distribution on the effect of inequality. The findings are in line with the argument that those in the middle should be most affected (Hypothesis 3). They do not support the expectation that those in the bottom are most affected (rejecting Hypothesis 2a).

Hypothesis $2 \mathrm{~b}$ further predicted that the effect of income inequality would be positive for the top income group. Returning to Model 2 of Table 1, the sum of coefficients for the Gini and the top income quintile $\times$ Gini interaction term is only barely positive $(-0.543+$ $0.549=0.006)$ and a Wald test of the sum of these two coefficients shows there is not a statistically significant difference from zero $(\mathrm{p}=.98)$. This does not support Hypotheses $2 \mathrm{~b}$. One possibility is that the top income quintile is too large a group, but in an additional model I found no positive effect for the top 10\% (available upon request). The data do not 
permit me to examine those at the extreme high end of the income distribution because the incomes of more than $5 \%$ of GSS respondents are top-coded each year.

\subsection{Robustness Models}

I also examined several alternative models and assessed the sensitivity of the results to a number of robustness tests. First, I estimated multilevel models with random incepts, both as a three-level model with random intercepts at the state, state-year, and individual level, and as a two-level model with crossed non-nested random intercepts at the state and the year level (Appendix Table A5). These models produce results with similar coefficients and smaller standard errors ("more" statistical significance) than the main models. This is not surprising because the random effects model is a more efficient estimator and uses variation both within and between groups.

Turning to the other extreme, I analyzed models that added year fixed effects to the main models (Appendix Table A4). In these models with two-way fixed effects, the magnitude and direction the coefficients are nearly the same as in the main results, but the standard errors of the estimates increase substantially and the results are not statistically significant at the conventional $\mathrm{p}<.05$ level. $^{8}$ Recall, however, that year controls net out much of the increase in inequality within states over the time period being examined. Although it is possible that some other trending characteristics are driving the main results, these unidentified characteristics would have to operate independently of the existing time-varying state-level controls (median income, population density, percent black, percent foreign born, and poverty rate).

I also considered models that treat the three-value measure of financial satisfaction as categorical; using both ordered logistic and multinomial logistic regression produces substantively identical results. The results were also robust to models using the income quintiles based on the ratio of household income to state-year median income, models controlling for household income alongside income quintile, models reestimated without survey weights, models that removed observations from the most and least unequal state in each year, and models with a one-year lagged Gini index.

\subsection{Counterfactual Simulation of Change Over Time}

The analysis presented so far assesses the effect of income inequality by using the state-level variation in inequality over time. Given, as shown in Figure 2, that state-level inequality rose over the period of analysis, what implications did that have for financial satisfaction? I examine this by comparing the observed trend in financial satisfaction to a counterfactual trend - based on the estimated model - of how financial satisfaction might have changed had income inequality not risen.

Figure 4 presents these results. First, the dotted green line shows the true level over time for financial satisfaction - the same as in Figure 1. Next, the short-dashed red lines show the outcome's level for each year based on the predicted values obtained by calculating the predicted values for all of the observations in the sample, using the observed values for all of the covariates. If the model is reasonable, this should be close to the observed values, which it is. Finally, the long-dashed blue line shows the counterfactual simulation that predicts

\footnotetext{
${ }^{8}$ Models with a year linear term and with year linear and quadratic terms produced substantively similar results.
} 
what financial satisfaction would have been in every year had income inequality remained constant since 1973, but everything had changed as it actually did. The figure demonstrates that had state-level inequality remained constant, the overall decline would have been about half of what it actually was. For example, the predicted gap between the counterfactual and predicted lines for 2012 is about .06 (about .08 standard deviations).

Figure 4: Counterfactual Simulation of Change Over Time in Financial Satisfaction

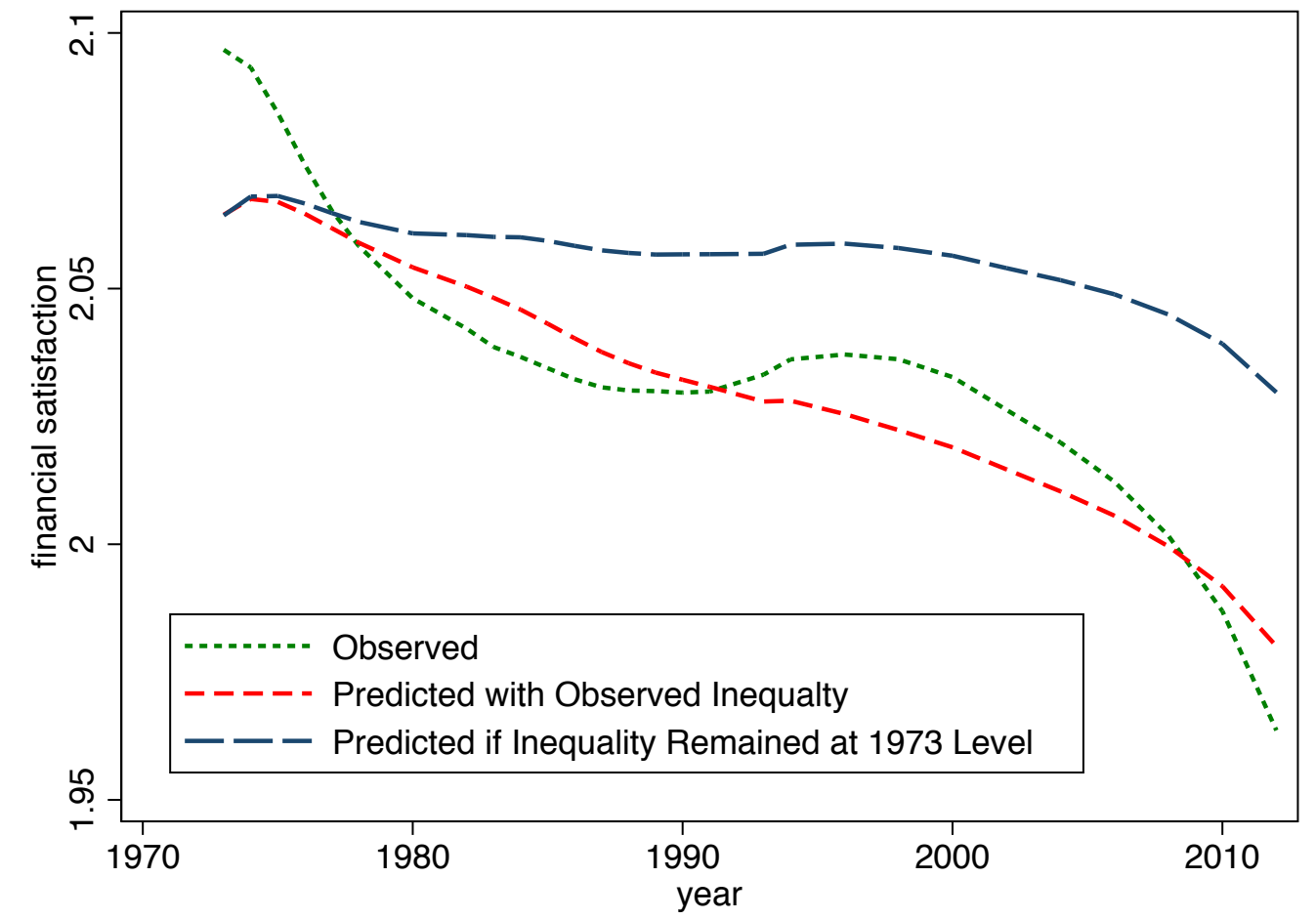

Note: Lines are lowess plots of data points aggregated by year.

Figure 5 presents the same results by income group. To avoid over-cluttering the figure, the true observed values are not shown, but the predicted line based on the actual inequality and the counterfactual line based on constant inequality are presented. From looking at the predicted values (red short dashes) it is clear that between 1972 and 2012 it was those in the bottom income quintile that experienced the greatest overall decline in their financial satisfaction (from 1.80 to 1.65). However, the largest gap attributable to income inequality is for those near the middle of the income distribution. The gap in 2012 between the predicted and counterfactual line for the middle quintile is 0.1 -almost double that of the overall effect from Figure 4. For the top quintile, there is no predicted change in financial satisfaction for the observed or counterfactual models over time, as seen by the nearly-flat, completely-overlapping lines at the top of the figure. 
Figure 5: Counterfactual Simulation of Change Over Time in Financial Satisfaction by Income Quintile

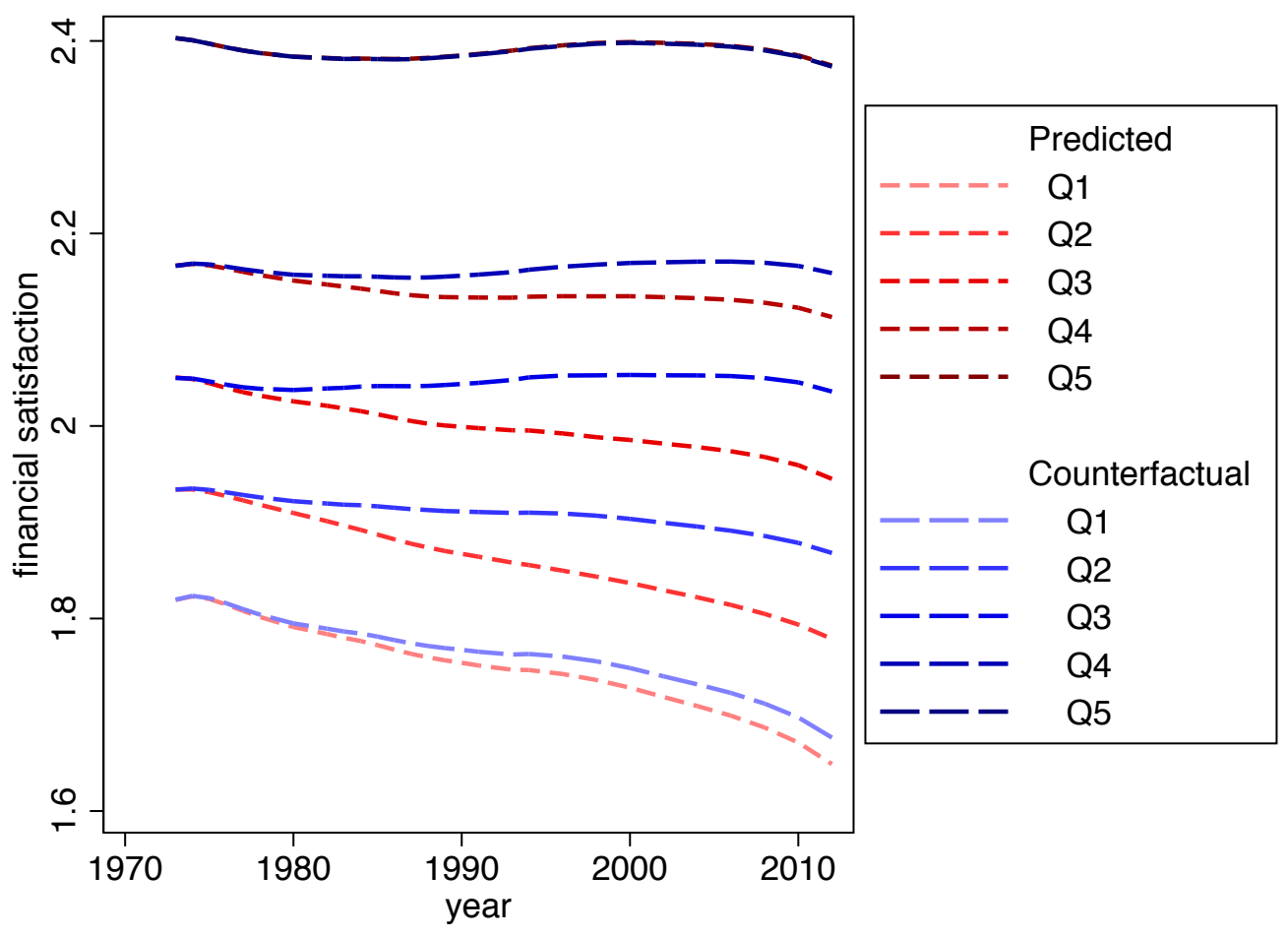

Note: Lines are lowess plots of data points aggregated by year and income group. Note for Q5 the predicted and counterfactual lines completely overlap.

\section{Discussion and Conclusion}

This paper examined the effect of rising state-level income inequality on financial satisfaction. Although the overall effect is negative, I find the middle to be the most negatively effected. This is consistent with the account that the middle class may be the most affected by income inequality. In the escalating "positional arms race," it is these households who likely experience a greater gap between their aspirations (the "American dream") and the economic reality they face (Schor 1998; Frank 2007; Dwyer 2009; Fligstein and Goldstein 2015).

I employed a counterfactual simulation to predict what the consequences of rising inequality have been for financial satisfaction between 1973 and 2012. Overall, the simulation suggests financial satisfaction would have declined only about half as much as it did. When breaking it down by income quintiles, I show that although those at the bottom experienced the largest decline in financial satisfaction, it is those in the middle whose decline is most attributable to rising income inequality.

Whether these effect sizes and over time declines are "large" depends on how much one thinks financial satisfaction is associated with other outcomes of interest. But small values can be substantively (as well as statistically) significant, especially when they apply to an entire population. If financial satisfaction (or the lack thereof) is a factor in the decisions people and families make about aspects of life ranging from work and leisure to indebtedness and voting preferences to marriage and fertility, then rising income inequality may be an 
important part of the story to focus on.

This paper embraces causal language throughout, referring to the "effects" of income inequality. Of course the analyses can only show associations between measures. As such, reverse causality cannot be entirely dismissed. It is possible that states where people are less satisfied with their finances are more likely to become unequal (though this would likely be a long-term process). But, I find the more straightforward direction of causality-income inequality causing the outcomes - far more plausible. A more likely problem is confounders. There are many differences between states and the people in them besides their Gini indices, and these differences could be driving some of the results (although this reasoning applied to popular cross-national work on inequality is even more concerning). This paper tries to deal with confounders by including a large number of additional covariates at the individual and state level, including state fixed effects.

Another possibility is that inequality works through a more dynamic causal relationship. For example, it is possible that past levels of income inequality, even net of the current level, also effect financial satisfaction. In such cases, the presence of state fixed effects could actually bias the results (Imai and Kim 2017). ${ }^{9}$ Relatedly, it may be that the changes in inequality levels, rather than the absolute levels themselves, may drive inequality's effects on financial satisfaction. Once a particular level of income inequality becomes normalized (whether high or low), it may have much less effect than when it is rapidly changing (Hirschman and Rothschild 1973; Schröder 2016; Esping-Andersen and Nedoluzhko 2017). Future research might take this into account by, for example, exploring the effects of a \% change in income inequality from some previous point in time.

Still other limitations revolve around the data. As noted in the Data and Methods section, income inequality in this analysis is measured with pre-tax and transfer income, yet disposable income is a better measure of what is available to spend on the positional goods that people may wish to acquire. While currently no state-level data series of post-tax and transfer income is available, developing this could be a fruitful avenue for future research (and would be useful when examining the effect of income inequality on a wide array of outcomes).

It is also possible that the association between income inequality and financial satisfaction is real but the explanation - feeling deprived relative to others - is not. For example many have argued for neo-material explanations (e.g., differences in healthcare or employment opportunities) to explain the associations found between income inequality and various problems in society (e.g. Deaton 2003; Lynch et al. 2000). Similarly, neo-material factors could affect financial satisfaction itself. Income inequality may drive up the cost of living, rather than just the living standards (there some evidence in the housing market, see Dong 2017). Future research could focus on directly accounting for the prices of goods to separate living standards from living costs when assessing the effects of income inequality. Likewise, as inequality increases, the rich might obtain more political power and try to limit public spending on things that benefit everyone and direct more of the spending towards what benefits themselves (e.g., Bartels 2008), leaving everyone else less satisfied. (However, others argue that higher inequality might mean that, because the rich are richer and they pay high taxes and give to philanthropic causes, they pay for "public goods" such as medical facilities, educational resources, and amenities that actually improve the lives of everyone

\footnotetext{
${ }^{9} \mathrm{My}$ results are robust to omitting state fixed effects (and, in fact, the statistically significant coefficients have larger effect sizes), but this reintroduces the unobserved time-invariant confounders being controlled for. See (Imai and Kim 2017) for one approach to deal with this.
} 
[e.g., Boustan et al. 2013]).

But the results of this paper actually provide good evidence for a relative deprivation explanation. If rising income inequality is linked to lower financial satisfaction because it reduces public goods or makes things more expensive, then everyone (except perhaps the highest earners) would be affected. However, we find that those in the middle of the income distribution are most affected. This is far more consistent with the argument that relative position - rather than absolute income or resources - is driving the findings.

Despite the limitations, this paper makes a significant contribution to our understanding of the effects of income inequality. Existing literature has frequently implied that psychosocial factors such as feelings of relative deprivation are important mediators for income inequality's effects on various social problems, but some critics have questioned this explanation, instead arguing for the supremacy of neo-material explanations (e.g. Deaton 2003; Lynch et al. 2000). Still others question whether there is really a relationship at all (e.g., Winship 2013).

Furthermore, classical sociological accounts of status have consistently noted that income (and economic standing, more generally) is only one dimension of social status. Weber (1946) described how "social honor" was typically expressed by members of "status groups" through what they consumed and their style of life. In The Civilizing Process, Elias ([1939] 1994) showed how forms of manner, dress, and politeness evolved so that nobles could distinguish themselves in an ongoing status competition within the kings' courts. As capitalism took hold, a new class of bourgeoisie with similar economic resources but non-noble birth began to emulate these behaviors, further escalating the creation of new ways to behave. Similarly Bourdieu (1984), in his study of lifestyles in Distinction, used survey data to map out a social field of France wherein status depended on at least two dimensions of resources: cultural capital and economic capital. In more recent work, Chan and Goldthorpe (2007) presented a significant difference between class and social status in British social life, and Goldthorpe (2010) pointed out - in a direct critique of Wilkinson and Pickett (2010) - that Japan has relatively low income inequality but a strong status hierarchy.

All this might suggest that income inequality would have little to no influence on individuals in normal life. Yet these results show that income inequality does make people feel more deprived and less satisfied with their financial situation. This in turn likely shapes their behaviors and attitudes, from everyday routines to major life decisions. To my knowledge, this is the first study to directly examine the link between income inequality and financial satisfaction, and it is an important step towards effectively evaluating and addressing the broader consequences of income inequality. 


\section{References}

Adjaye-Gbewonyo, Kafui and Ichiro Kawachi. 2012. "Use of the Yitzhaki Index As a Test of Relative Deprivation for Health Outcomes: A Review of Recent Literature." Social Science \& Medicine 75(1):129-37.

Aguiar, Mark and Mark Bils. 2015. "Has Consumption Inequality Mirrored Income Inequality?" American Economic Review 105(9):2725-2756.

Akhand, Hafiz and Haoming Liu. 2002. "Income Inequality in the United States: What the Individual Tax Files Say." Applied Economics Letters 9(4):255-259.

Ash, Michael and Dean Robinson. 2009. "Inequality, Race, and Mortality in U.S. Cities: A Political and Econometric Review of Deaton and Lubotsky (56:6, 1139-1153, 2003)." Social Science EJ Medicine 68(11):1909-1913.

Atkinson, Anthony B. and François Bourguignon (eds.). 2015. Handbook of Income Distribution, volume 2. Elsevier.

Attanasio, Orazio P., Erik Hurst, and Luigi Pistaferri. 2015. "The Evolution of Income, Consumption, and Leisure Inequality in the US, 1980-2010." In Improving the Measurement of Consumer Expenditures, edited by Christopher D. Carroll, Thomas F. Crossley, and John Sabelhaus, chapter 4. University of Chicago Press.

Attanasio, Orazio P. and Luigi Pistaferri. 2016. "Consumption Inequality." Journal of Economic Perspectives 30(2):3-28.

Bartels, Larry M. 2008. Unequal Democracy: The Political Economy of the New Gilded Age. Princeton, NJ: Princeton University Press.

Bourdieu, Pierre. 1984. Distinction. Cambridge: Harvard University Press.

Boustan, Leah, Fernando Ferreira, Hernan Winkler, and Eric Zolt. 2013. "The Effect of Rising Income Inequality on Taxation and Public Expenditures: Evidence from US Municipalities and School Districts, 1970-2000." Review of Economics and Statistics 95:12911302.

Bricker, Jesse, Rodney Ramcharan, and Jacob Krimmel. 2014. "Signaling Status: The Impact of Relative Income on Household Consumption and Financial Decisions." Finance and Economics Discussion Series 2014-76. Board of Governors of the Federal Reserve System (U.S.) .

Cameron, Colin and Douglas Miller. 2011. "Robust Inference with Clustered Data." In Handbook of Empirical Economics and Finance, edited by A. Ullah and D. E. Giles., pp. 1-28. CRC Press.

Chan, Tak Wing and John H. Goldthorpe. 2007. "Class and Status: The Conceptual Distinction and its Empirical Relevance." American Sociological Review 72:512-532.

Davis, James. 1959. "A Formal Interpretation of the Theory of Relative Deprivation." Sociometry 22(4):280-296. 
Deaton, Angus. 2003. "Health, Inequality, and Economic Development." Journal of Economic Literature 41(1):113-158.

Deaton, Angus and Darren Lubotsky. 2003. "Mortality, Inequality and Race in American Cities and States." Social Science \& Medicine 56:1139-1153.

DePianto, David E. 2011. "Financial Satisfaction and Perceived Income Through a Demographic Lens: Do Different Race/Gender Pairs Reap Different Returns to Income?" Social Science Research 40(3):773-783.

Diener, Ed and Robert Biswas-Diener. 2002. "Will Money Increase Subjective Well-Being? A Literature Review and Guide to Needed Research." Social Indicators Research 57:119-69.

Diener, Ed and S. Oishi. 2000. "Money and Happiness: Income and Subjective Well-Being Across Nations." In Subjective Well-Being Across Cultures, edited by E. Diener and E. M. Suh. Cambridge, MA: MIT Press.

Dong, Hongwei. 2017. "The impact of income inequality on rental affordability: An empirical study in large American metropolitan areas." Urban Studies pp. 1-17.

Duesenberry, James. 1949. Income, Savings, and the Theory of Consumer Behavior. Cambridge, MA: Harvard University Press.

Dwyer, Rachel E. 2009. "The McMansionization of America? Income Stratification and the Standard of Living in Housing, 1960-2000." Research in Social Stratification and Mobility $27: 285-300$.

Easterlin, Richard. 2006. "Life Cycle Happiness and Its Sources: Intersections of Psychology, Economics and Demography." Journal of Economic Psychology 27(4):463-482.

Easterlin, Richard, L. Angelescu-McVey, M. Switek, O. Sawangfa, and J. S. Zweig. 2010. "The Happiness-Income Paradox Revisited." Proceedings of National Academy of Sciences 107(52):22463-22468.

Easterlin, Richard A. 1973. "Does Money Buy Happiness?" The Public Interest 30:3-10.

Elias, Norbert. [1939] 1994. The Civilizing Process. Oxford: Blackwell Press.

Esping-Andersen, Gøsta and Lesia Nedoluzhko. 2017. "Inequality equilibria and individual well-being." Social Science Research 62:24-28.

Evans, William, Michael Hout, and Susan Mayer. 2004. "Assessing the Effect of Economic Inequality." In Social Inequality, edited by Kathryn Neckerman, pp. 933-968. Russell Sage Foundation.

Ferreira, Francisco H. G., Nora Lustig, and Daniel Teles. 2015. "Appraising Cross-National Income Inequality Databases: An Introduction." The Journal of Economic Inequality 13 (4):497-526.

Fischer, Claude S. 2008. "What Wealth-Happiness Paradox? A Short Note on the American Case." Journal of Happiness Studies 9(2):219-226. 
Fisher, Jonathan D., David S. Johnson, and Timothy M. Smeeding. 2013. "Measuring the Trends in Inequality of Individuals and Families: Income and Consumption." The American Economic Review 103(3):184-188.

Fligstein, Neil and Adam Goldstein. 2015. "The Emergence of a Finance Culture in American Households, 1989-2007." Socio-Economic Review 13(3):575-601.

Fligstein, Neil, Orestes P. Hastings, and Adam Goldstein. 2017. "Keeping up with the Joneses: How Households Fared in the Era of High Income Inequality and the Housing Price Bubble, 1999-2007." Socius: Sociological Research for a Dynamic World 3:1-15.

Frank, Mark. 2014. "A New State-Level Panel of Annual Inequality Measures over the Period 1916-2005." Journal of Business Strategies 31(1):241-263.

Frank, Robert. 2007. Falling Behind: How Rising Inequality Harms the Middle Class. University of California Press.

Gelman, Andrew and Jennifer Hill. 2007. Data Analysis Using Regression and Multilevel/hierarchical Models. Cambridge: Cambridge University Press.

Goldstein, Adam and Orestes P. Hastings. 2018. "Buying In: Positional Competition, Schools, and Housing Consumption." Working paper.

Goldthorpe, John H. 2010. "Analysing Social Inequality: A Critique of Two Recent Contributions from Economics and Epidemiology." European Sociological Review 26(6):731-744.

Guillaud, Elvire, Matthew Olckers, and Michaël Zemmour. 2017. "Four levers of redistribution: The impact of tax and transfer systems on inequality reduction." LIS Working Paper Series No. 695.

Hastings, Orestes P. 2018. "Less Equal, Less Trusting? Reexamining Longitudinal and Cross-sectional Effects of Income Inequality on Trust in U.S. States, 1973-2012." Social Science Research 74:77-95.

Hauser, Oliver P and Michael I Norton. 2017. "(Mis)perceptions of inequality." Current Opinion in Psychology 18:21-25.

Hirsch, Fred. 1977. The Social Limits to Growth. London: Routledge \& Kegan Paul.

Hirschman, Albert O. and Michael Rothschild. 1973. "The Changing Tolerance for Income Inequality in the Course of Economic Development." The Quarterly Journal of Economics $87: 544-566$.

Hout, Michael. 2004. "Getting the Most out of the GSS Income Measures." GSS Methodological Report 101.

Hout, Michael and Joshua Goldstein. 1994. "How 4.5 Million Irish Immigrants Came to Be 41 Million Irish Americans: Demographic, Social, and Subjective Components of the Ethnic Composition of the White Population of the United States." American Sociological Review 59:64-82. 
Hümbelin, Oliver and Rudolf Farys. 2016. "The Suitability of Tax Data to Study Trends in Inequality - A Theoretical and Empirical Review with Tax Data from Switzerland." Research in Social Stratification and Mobility 44:136-150.

Iceland, John. 2012. Poverty in America: A Handbook. Berkeley, CA: University of California Press.

Imai, Kosuke and In Song Kim. 2017. "When Should We Use Fixed Effects Regression Models for Causal Inference with Longitudinal Data?" Working Paper online at http: //web.mit.edu/insong/www/pdf/FEmatch.pdf.

Joo, So-Hyun and John E. Grable. 2004. "An Exploratory Framework of the Determinants of Financial Satisfaction." Journal of Family and Economic Issues 25:25-50.

Kalleberg, Arne and Peter V. Marsden. 2012. "Labor Force Insecurity and U.S. Work Attitudes, 1970s-2006." In Social Trends in American Life, edited by Peter V. Marsden, pp. 315-337. Princeton: Princeton University Press.

Keister, Lisa A. and Hang Young Lee. 2017. "The Double One Percent: Identifying an Elite and a Super-Elite using the Joint Distribution of Income and Net Worth." Research in Social Stratification and Mobility 50:1-12.

Kenworthy, Lane. 2016. The Good Society. Online at http://lanekenworthy.net/ thegoodsociety.

Krueger, Dirk and Fabrizio Perri. 2006. "Does Income Inequality Lead to Consumption Inequality? Evidence and Theory." Review of Economic Studies 73(1):163-193.

Layte, Richard and Christopher Whelan. 2014. "Who Feels Inferior? A Test of the Status Anxiety Hypothesis of Social Inequalities in Health." European Sociological Review 30 (4):525-535.

Ligon, Ethan. [1989] 1994. "The Development and Use of a Consistent Income Measure for the General Social Survey." GSS Methodological Report 64.

Lynch, John, George Davey Smith, George Kaplan, and James House. 2000. "Income Inequality and Mortality: Importance to Health of Individual Income, Psychosocial Environment, or Material Conditions." BMJ 320:1200-1204.

Marx, Karl. 1847 [1972]. "Wage Labor and Capital." In The Marx-Engels Reader, edited by Robert Tucker. W. W. Norton \& Company.

McCall, Leslie. 2013. The Undeserving Rich: American Beliefs About Inequality, Opportunity, and Redistribution. New York: Cambridge University Press.

Merton, Robert and Alice Rossi. 1950. "Contributions to the Theory of Reference Group Behavior." In Continuities in Social Research, edited by Robert Merton and Paul Lazarsfeld, pp. 40-115. New York: Free Press.

Meyer, Bruce D., Wallace K. C. Mok, and James X. Sullivan. 2015. "Household Surveys in Crisis." Journal of Economic Perspectives 29(4):199-226. 
Meyer, Bruce D. and James X. Sullivan. 2017. "Consumption and Income Inequality in the U.S. Since the 1960s." NBER Working Paper No. 23655.

Moss, David, Anant Thaker, and Howard Rudnick. 2013. "Inequality and Decision Making: Imagining a New Line of Inquiry." Harvard Business School Working Paper 13-099.

Neckerman, Kathryn and Florencia Torche. 2007. "Inequality: Causes and Consequences." Annual Review of Sociology 33:335-357.

Paskov, Marii, Klarita Gërxhani, and G. Van de Werfhorst Herman. 2017. "Giving up on the Joneses? the Relationship Between Income Inequality and Status-Seeking." European Sociological Review 33(1):112-123.

Pickett, Kate and Richard G. Wilkinson. 2015. "Income Inequality and Health: A Causal Review." Social Science \& Medicine 128:316-326.

Piketty, Thomas. 2014. Capital in the Twenty-First Century. Boston, MA: Harvard University Press.

Piketty, Thomas and Emmanuel Saez. 2003 [2015]. "Income Inequality in the United States, 1913-1998." Quarterly Journal of Economics 118(1):1-39.

Rabe-Hesketh, Sophia and Anders Skrondal. 2012. Multilevel and Longitudinal Modeling Using Stata (3rd Edition). College Station, TX: Stata Press.

Richard, Burkhauser, Shuaizhang Feng, Stephen Jenkins, and Jeff Larrimore. 2009. "Recent Trends in Top Incomes Shares in the USA: Reconciling Estimates from March CPS and IRS Tax Return Data." NBER Working Paper 15320.

Rosenfeld, Jake. 2017. "Don’t Ask or Tell: Pay Secrecy Policies in U.S. Workplaces." Social Science Research 65:1-16.

Runciman, Walter G. 1966. Relative Deprivation and Social Justice. London: Routledge \& Kegan Paul.

Saez, Emmanuel and Gabriel Zucman. 2016. "Wealth Inequality in the United States Since 1913: Evidence from Capitalized Income Tax Data." Quarterly Journal of Economics 131 (2):519-578.

Schnittker, Jason. 2008. "Diagnosing Our National Disease: Trends in Income and Happiness, 1973 to 2004." Social Psychology Quarterly 71(3):257-280.

Schor, Juliet. 1998. The Overspent American. New York: Basic Books.

Schröder, Martin. 2016. "Article Navigation How Income Inequality Influences Life Satisfaction: Hybrid Effects Evidence from the German SOEP." European Sociological Review $32(2): 307-320$.

Smith, Tom, Peter Marsden, Michael Hout, and Jibum Kim. 2013. General Social Surveys, 1972-2012. Chicago: National Opinion Research Center [producer]; Storrs, CT: The Roper Center for Public Opinion Research, University of Connecticut [distributor]. 
Stevenson, Betsey and Justin Wolfers. 2008. "Economic Growth and Happiness: Reassessing the Easterlin Paradox." Brookings Papers on Economic Activity 1-87.

Stevenson, Betsey and Justin Wolfers. 2013. "Subjective Well-Being and Income: Is There Any Evidence of Satiation?" American Economic Review, Papers and Proceedings 103 (3):598-604.

Stone, Chad, Danilo Trisi, Arloc Sherman, and Emily Horton. 2016. "A Guide to Statistics on Historical Trends in Income Inequality." Technical report, Center on Budget and Policy Priorities.

Van de Werfhorst, Herman G. and Wiemer Salverda. 2012. "Consequences of economic inequality: Introduction to a special issue." Research in Social Stratification and Mobility 30:377-387.

Van Praag, B. M. S., P. Frijters, and A. Ferrer i Carbonell:. 2003. "The Anatomy of WellBeing." Journal of Economic Behavior and Organization 51:29-49.

Veblen, Thorstein. [1899] 1963. A Theory of the Leisure Class: An Economic Study of Institutions. New York: New American Library.

Walasek, Lukasz and Gordon D. A. Brown. 2015. "Income Inequality and Status Seeking Searching for Positional Goods in Unequal US States." Psychological Science 26(4):527533.

Walasek, Lukasz and Gordon D. A. Brown. 2016. "Income Inequality, Income, and Internet Searches for Status Goods: A Cross-National Study of the Association Between Inequality and Well-Being." Social Indicators Research 129:1001-1014.

Weber, Max. 1946. From Max Weber: Essays in Sociology. Edited by Hans Gerth and C. Wright Mills. New York: Oxford University Press.

Wilkinson, Richard and Kate Pickett. 2009. "Income Inequality and Social Dysfunction." Annual Review of Sociology 35:493-511.

Wilkinson, Richard and Kate Pickett. 2010. The Spirit Level: Why Equality Is Better for Everyone. New York: Bloomsbury Press.

Winship, Scott. 2013. "Overstating the Costs of Inequality." National Affairs 15:33-49.

Yitzhaki, Shlomo. 1979. "Relative Deprivation and the Gini Coefficient." The Quarterly Journal of Economics 93(2):321-324. 


\section{Appendix}

Table A1: Descriptives

\begin{tabular}{|c|c|c|c|c|}
\hline & mean & sd & $\min$ & $\max$ \\
\hline Financial satisfaction & 2.02 & 0.74 & 1 & 3 \\
\hline State gini & 0.56 & 0.06 & 0.43 & 0.71 \\
\hline Income quintile 1 (bottom) & 0.19 & & 0 & 1 \\
\hline Income quintile 2 & 0.20 & & 0 & 1 \\
\hline Income quintile 3 & 0.19 & & 0 & 1 \\
\hline Income quintile 4 & 0.21 & & 0 & 1 \\
\hline Income quintile 5 (top) & 0.20 & & 0 & 1 \\
\hline Female & 0.53 & & 0 & 1 \\
\hline Age (years) & 44.14 & 16.67 & 18 & 89 \\
\hline$($ Age $x$ Age $) / 100$ & 22.26 & 16.26 & 3.24 & 79.2 \\
\hline Non-Hispanic white & 0.77 & & 0 & 1 \\
\hline Non-Hispanic black & 0.13 & & 0 & 1 \\
\hline Non-Hispanic other & 0.03 & & 0 & 1 \\
\hline Hispanic & 0.08 & & 0 & 1 \\
\hline Married & 0.61 & & 0 & 1 \\
\hline Widowed & 0.06 & & 0 & 1 \\
\hline Divorced & 0.10 & & 0 & 1 \\
\hline Separated & 0.03 & & 0 & 1 \\
\hline Never married & 0.21 & & 0 & 1 \\
\hline Number of adults & 2.23 & 0.92 & 1 & 8 \\
\hline Number of children & 1.96 & 1.79 & 0 & 8 \\
\hline Religious service attendance & 3.80 & 2.71 & 0 & 8 \\
\hline Years of education & 12.93 & 3.08 & 0 & 20 \\
\hline Working fulltime & 0.52 & & 0 & 1 \\
\hline Working parttime & 0.11 & & 0 & 1 \\
\hline Temporality not working & 0.02 & & 0 & 1 \\
\hline Unemployed & 0.04 & & 0 & 1 \\
\hline Retired & 0.11 & & 0 & 1 \\
\hline Student & 0.04 & & 0 & 1 \\
\hline Keeping house & 0.15 & & 0 & 1 \\
\hline Other work status & 0.02 & & 0 & 1 \\
\hline Democrat & 0.49 & & 0 & 1 \\
\hline Republican & 0.35 & & 0 & 1 \\
\hline Other party; No party & 0.16 & & 0 & 1 \\
\hline Urban & 0.60 & & 0 & 1 \\
\hline Suburban & 0.27 & & 0 & 1 \\
\hline Rural & 0.13 & & 0 & 1 \\
\hline State median income (logged) & 10.87 & 0.14 & 10.4 & 11.3 \\
\hline State percent foreign born & 0.09 & 0.07 & 0.0070 & 0.27 \\
\hline State population density (logged) & 4.98 & 0.99 & 0.017 & 9.28 \\
\hline State percent black & 0.13 & 0.08 & 0.0023 & 0.71 \\
\hline State poverty rate & 13.48 & 3.35 & 2.90 & 27.2 \\
\hline
\end{tabular}

Note: $\mathrm{N}=51699$. Individual measures are weighted to account for sampling. State Gini index variable is reported before mean centering. State median income is adjusted to 2012 dollars using the CPI-U-RS. Sources: General Social Survey: 1973-2012. Census: 1970, 1980, 1990, 2000. American Community Survey: 2006-2012. IRS Statistics of Income: 1973-2012. 
Table A2: Correlation Table of State Level Variables

\begin{tabular}{lcccccc}
\hline & 1. & 2. & 3. & 4. & 5. & 6. \\
\hline 1. State Gini & 1.00 & & & & & \\
2. State median income (logged) & 0.17 & 1.00 & & & & \\
3. State percent foreign born & 0.56 & 0.46 & 1.00 & & & \\
4. State population density (logged) & 0.07 & 0.36 & 0.42 & 1.00 & & \\
5. State percent black & 0.11 & -0.25 & -0.07 & 0.35 & 1.00 & \\
6. State poverty rate & 0.18 & -0.70 & 0.03 & -0.18 & 0.38 & 1.00 \\
\hline
\end{tabular}

Census: 1970, 1980, 1990, 2000. American Community Survey: 2006-2012. IRS Statistics of Income: 1973-2012. 
Table A3: Full Regression Coefficients from Main Models of Financial Satisfaction

\begin{tabular}{|c|c|c|c|c|}
\hline & (1) & & $(2)$ & \\
\hline State Gini & $-0.30^{*}$ & $(0.13)$ & $-0.54^{* *}$ & $(0.20)$ \\
\hline Q1 (bottom) & $-0.30^{* * *}$ & $(0.014)$ & $-0.30^{* * *}$ & $(0.014)$ \\
\hline Q2 & $-0.16^{* * *}$ & $(0.0091)$ & $-0.16^{* * *}$ & $(0.0091)$ \\
\hline Q3 & ref. & & ref. & \\
\hline Q4 & $0.16^{* * *}$ & $(0.012)$ & $0.16^{* * *}$ & $(0.011)$ \\
\hline Q5 (top) & $0.41^{* * *}$ & $(0.016)$ & $0.41^{* * *}$ & $(0.015)$ \\
\hline Q1 (bottom) $\times$ Gini & & & $0.38^{*}$ & $(0.17)$ \\
\hline Q2 $\times$ Gini & & & 0.0032 & $(0.13)$ \\
\hline Q3 $\times$ Gini & & & ref. & \\
\hline Q4 × Gini & & & 0.27 & $(0.21)$ \\
\hline Q5 (top) $\times$ Gini & & & $0.55^{*}$ & $(0.25)$ \\
\hline Female & 0.0095 & $(0.0097)$ & 0.0093 & $(0.0096)$ \\
\hline Age (years) & $-0.019^{* * *}$ & $(0.0013)$ & $-0.019^{* * *}$ & $(0.0013)$ \\
\hline$($ Age $x$ Age $) / 10$ & $0.028^{* * *}$ & $(0.0015)$ & $0.028^{* * *}$ & $(0.0015)$ \\
\hline Non-Hispanic white & ref. & & ref. & \\
\hline Non-Hispanic black & $-0.12^{* * *}$ & $(0.013)$ & $-0.12^{* * *}$ & $(0.013)$ \\
\hline Non-Hispanic other & $0.085^{* *}$ & $(0.025)$ & $0.084^{* *}$ & $(0.025)$ \\
\hline Hispanic & 0.013 & $(0.015)$ & 0.015 & $(0.016)$ \\
\hline Married & ref. & & ref. & \\
\hline Widowed & $-0.064^{* * *}$ & $(0.013)$ & $-0.062^{* * *}$ & $(0.013)$ \\
\hline Divorced & $-0.11^{* * *}$ & $(0.0095)$ & $-0.11^{* * *}$ & $(0.0091)$ \\
\hline Separated & $-0.11^{* * *}$ & $(0.024)$ & $-0.11^{* * *}$ & $(0.024)$ \\
\hline Never Married & $0.066^{* * *}$ & $(0.011)$ & $0.068^{* * *}$ & $(0.011)$ \\
\hline Number of adults & $-0.034^{* * *}$ & $(0.0047)$ & $-0.033^{* * *}$ & $(0.0046)$ \\
\hline Number of children & $-0.019^{* * *}$ & $(0.0024)$ & $-0.018^{* * *}$ & $(0.0024)$ \\
\hline Religious service attendance & $0.020^{* * *}$ & $(0.0024)$ & $0.020^{* * *}$ & $(0.0024)$ \\
\hline Years of education & 0.0027 & $(0.0015)$ & 0.0026 & $(0.0015)$ \\
\hline Urban & $r e f$ & & $r e f$ & \\
\hline Suburban & $-0.024^{*}$ & $(0.012)$ & $-0.024^{*}$ & $(0.012)$ \\
\hline Rural & $0.036^{* *}$ & $(0.013)$ & $0.035^{* *}$ & $(0.013)$ \\
\hline Full time & ref. & & ref. & \\
\hline Part time & -0.009 & $(0.010)$ & -0.0095 & $(0.010)$ \\
\hline Temp not wrk & -0.0097 & $(0.025)$ & -0.0097 & $(0.025)$ \\
\hline Unemployed & $-0.31^{* * *}$ & $(0.025)$ & $-0.32^{* * *}$ & $(0.026)$ \\
\hline Retired & $0.090^{* * *}$ & $(0.021)$ & $0.089^{* * *}$ & $(0.021)$ \\
\hline In school & $0.058^{*}$ & $(0.023)$ & $0.058^{*}$ & $(0.023)$ \\
\hline Keeping house & $0.043^{* * *}$ & $(0.0088)$ & $0.043^{* * *}$ & $(0.0088)$ \\
\hline Other work status & $-0.10^{* * *}$ & $(0.028)$ & $-0.11^{* * *}$ & $(0.028)$ \\
\hline Democrat & ref. & & ref. & \\
\hline Republican & $0.063^{* * *}$ & $(0.0087)$ & $0.063^{* * *}$ & $(0.0087)$ \\
\hline Other party; no party & -0.0043 & $(0.012)$ & -0.0035 & $(0.012)$ \\
\hline State median income (logged) & 0.14 & $(0.092)$ & 0.14 & $(0.092)$ \\
\hline State percent foreign born & 0.11 & $(0.36)$ & 0.035 & $(0.35)$ \\
\hline State population density (logged) & -0.16 & $(0.083)$ & -0.15 & $(0.083)$ \\
\hline State percent black & -0.25 & $(0.39)$ & -0.23 & $(0.39)$ \\
\hline State poverty rate & $-0.011^{* * *}$ & $(0.0031)$ & $-0.011^{* * *}$ & $(0.0031)$ \\
\hline State Fixed Effects & Yes & & Yes & \\
\hline Observations & 51699 & & 51699 & \\
\hline
\end{tabular}

Standard errors in parentheses

${ }^{*} p<.05,{ }^{* *} p<.01,{ }^{* * *} p<.001$

Note: The middle income quintile (Q3) is the baseline category. Each model uses sampling weights and the standard errors are adjusted for clustering within states. 
Table A4: Regression Coefficients from Models of Financial Satisfaction with Year Fixed Effects

\begin{tabular}{|c|c|c|c|c|}
\hline & $(1)$ & & $(2)$ & \\
\hline State Gini & -0.34 & $(0.27)$ & -0.58 & $(0.33)$ \\
\hline Q1 (bottom) & $-0.30^{* * *}$ & $(0.014)$ & $-0.30^{* * *}$ & $(0.014)$ \\
\hline Q2 & $-0.16^{* * *}$ & $(0.0091)$ & $-0.16^{* * *}$ & $(0.0091)$ \\
\hline Q3 & ref. & & ref. & \\
\hline Q4 & $0.16^{* * *}$ & $(0.012)$ & $0.16^{* * *}$ & $(0.011)$ \\
\hline Q5 (top) & $0.42^{* * *}$ & $(0.015)$ & $0.42^{* * *}$ & $(0.014)$ \\
\hline Q1 (bottom) $\times$ Gini & & & $0.38^{*}$ & $(0.17)$ \\
\hline Q2 $\times$ Gini & & & -0.0087 & $(0.13)$ \\
\hline Q3 $\times$ Gini & & & ref. & \\
\hline Q4 $\times$ Gini & & & 0.28 & $(0.21)$ \\
\hline Q5 (top) $\times$ Gini & & & $0.52^{*}$ & $(0.25)$ \\
\hline Female & 0.0097 & $(0.0093)$ & 0.0095 & $(0.0093)$ \\
\hline Age (years) & $-0.020^{* * *}$ & $(0.0013)$ & $-0.020^{* * *}$ & $(0.0013)$ \\
\hline$($ Age $x$ Age $) / 10$ & $0.028^{* * *}$ & $(0.0015)$ & $0.028^{* * *}$ & $(0.0015)$ \\
\hline Non-Hispanic white & ref. & & ref. & \\
\hline Non-Hispanic black & $-0.12^{* * *}$ & $(0.013)$ & $-0.12^{* * *}$ & $(0.013)$ \\
\hline Non-Hispanic other & $0.084^{* *}$ & $(0.025)$ & $0.083^{* *}$ & $(0.025)$ \\
\hline Hispanic & 0.014 & $(0.014)$ & 0.017 & $(0.015)$ \\
\hline Married & ref. & & ref. & \\
\hline Widowed & $-0.063^{* * *}$ & $(0.012)$ & $-0.062^{* * *}$ & $(0.012)$ \\
\hline Divorced & $-0.11^{* * *}$ & $(0.0092)$ & $-0.11^{* * *}$ & $(0.0088)$ \\
\hline Separated & $-0.11^{* * *}$ & $(0.024)$ & $-0.11^{* * *}$ & $(0.024)$ \\
\hline Never Married & $0.067^{* * *}$ & $(0.011)$ & $0.069^{* * *}$ & $(0.011)$ \\
\hline Number of adults & $-0.034^{* * *}$ & $(0.0046)$ & $-0.033^{* * *}$ & $(0.0046)$ \\
\hline Number of children & $-0.019^{* * *}$ & $(0.0023)$ & $-0.018^{* * *}$ & $(0.0023)$ \\
\hline Religious service attendance & $0.020^{* * *}$ & $(0.0024)$ & $0.020^{* * *}$ & $(0.0024)$ \\
\hline Years of education & 0.0027 & $(0.0015)$ & 0.0027 & $(0.0015)$ \\
\hline Urban & ref. & & ref. & \\
\hline Suburban & $-0.025^{*}$ & $(0.011)$ & $-0.025^{*}$ & $(0.011)$ \\
\hline Rural & $0.036^{* *}$ & $(0.013)$ & $0.035^{* *}$ & $(0.013)$ \\
\hline Full time & ref. & & ref. & \\
\hline Part time & -0.0076 & $(0.010)$ & -0.008 & $(0.010)$ \\
\hline Temp not working & -0.0097 & $(0.025)$ & -0.0097 & $(0.025)$ \\
\hline Unemployed & $-0.31^{* * *}$ & $(0.024)$ & $-0.31^{* * *}$ & $(0.025)$ \\
\hline Retired & $0.090^{* * *}$ & $(0.021)$ & $0.089^{* * *}$ & $(0.021)$ \\
\hline In school & $0.058^{*}$ & $(0.023)$ & $0.058^{*}$ & $(0.023)$ \\
\hline Keeping house & $0.045^{* * *}$ & $(0.0089)$ & $0.044^{* * *}$ & $(0.0089)$ \\
\hline Other work status & $-0.10^{* * *}$ & $(0.027)$ & $-0.10^{* * *}$ & $(0.027)$ \\
\hline Democrat & ref. & & ref. & \\
\hline Republican & $0.062^{* * *}$ & $(0.0089)$ & $0.062^{* * *}$ & $(0.0089)$ \\
\hline Other party; no party & -0.0046 & $(0.012)$ & -0.0039 & $(0.012)$ \\
\hline State median income (logged) & -0.00017 & $(0.082)$ & -0.0013 & $(0.082)$ \\
\hline State percent foreign born & -0.057 & $(0.30)$ & -0.13 & $(0.30)$ \\
\hline State population density (logged) & -0.086 & $(0.081)$ & -0.075 & $(0.080)$ \\
\hline State percent black & 0.048 & $(0.38)$ & 0.057 & $(0.38)$ \\
\hline State poverty rate & -0.0049 & $(0.0033)$ & -0.005 & $(0.0033)$ \\
\hline State Fixed Effects & Yes & & Yes & \\
\hline Year Fixed Effects & Yes & & Yes & \\
\hline Observations & 51699 & & 51699 & \\
\hline
\end{tabular}

Standard errors in parentheses

${ }^{*} p<.05,{ }^{* *} p<.01,{ }^{* * *} p<.001$

Note: The middle income quintile (Q3) is the baseline category. Each model uses sampling weights and the standard errors are adjusted for clustering within states. 
Table A5: Regression Coefficients from Multilevel Models of Financial Satisfaction

\begin{tabular}{|c|c|c|c|c|}
\hline \multirow[b]{2}{*}{ State Gini } & \multicolumn{2}{|c|}{$\begin{array}{c}(1) \\
\text { Financial satisfaction }\end{array}$} & \multicolumn{2}{|c|}{$\begin{array}{c}(2) \\
\text { Financial satisfaction }\end{array}$} \\
\hline & $-0.42^{* * *}$ & $(0.12)$ & $-0.59^{* * *}$ & $(0.16)$ \\
\hline Q1 (bottom) & $-0.32^{* * *}$ & $(0.010)$ & $-0.32^{* * *}$ & $(0.010)$ \\
\hline Q2 & $-0.17^{* * *}$ & $(0.0095)$ & $-0.17^{* * *}$ & $(0.0095)$ \\
\hline Q3 & ref. & & ref. & \\
\hline Q4 & $0.17^{* * *}$ & $(0.0097)$ & $0.17^{* * *}$ & $(0.0097)$ \\
\hline Q5 (top) & $0.40^{* * *}$ & $(0.011)$ & $0.40^{* * *}$ & $(0.011)$ \\
\hline Q1 (bottom) $\times$ Gini & & & 0.25 & $(0.15)$ \\
\hline Q2 × Gini & & & -0.033 & $(0.15)$ \\
\hline Q3 $\times$ Gini & & & ref. & \\
\hline Q4 $\times$ Gini & & & 0.26 & $(0.15)$ \\
\hline Q5 (top) $\times$ Gini & & & $0.37^{*}$ & $(0.16)$ \\
\hline Female & 0.0017 & $(0.0069)$ & 0.0016 & $(0.0069)$ \\
\hline Age (years) & $-0.017^{* * *}$ & $(0.0012)$ & $-0.017^{* * *}$ & $(0.0012)$ \\
\hline$($ Age $x$ Age $) / 10$ & $0.026^{* * *}$ & $(0.0012)$ & $0.026^{* * *}$ & $(0.0012)$ \\
\hline Non-Hispanic white & ref. & & ref. & \\
\hline Non-Hispanic black & $-0.12^{* * *}$ & $(0.010)$ & $-0.12^{* * *}$ & $(0.010)$ \\
\hline Non-Hispanic other & $0.049^{*}$ & $(0.020)$ & $0.049^{*}$ & $(0.020)$ \\
\hline Hispanic & 0.0064 & $(0.013)$ & 0.008 & $(0.013)$ \\
\hline Married & ref. & & ref. & \\
\hline Widowed & -0.020 & $(0.013)$ & -0.019 & $(0.013)$ \\
\hline Divorced & $-0.095^{* * *}$ & $(0.010)$ & $-0.094^{* * *}$ & $(0.010)$ \\
\hline Separated & $-0.12^{* * *}$ & $(0.017)$ & $-0.12^{* * *}$ & $(0.017)$ \\
\hline Never Married & $0.063^{* * *}$ & $(0.0099)$ & $0.065^{* * *}$ & $(0.0099)$ \\
\hline Number of adults & $-0.030^{* * *}$ & $(0.0043)$ & $-0.029^{* * *}$ & $(0.0043)$ \\
\hline Number of children & $-0.020^{* * *}$ & $(0.0021)$ & $-0.019^{* * *}$ & $(0.0021)$ \\
\hline Religious service attendance & $0.019^{* * *}$ & $(0.0012)$ & $0.019^{* * *}$ & $(0.0012)$ \\
\hline Years of education & $0.0026^{*}$ & $(0.0012)$ & $0.0026^{*}$ & $(0.0012)$ \\
\hline Urban & ref. & & ref. & \\
\hline Suburban & $-0.027^{* * *}$ & $(0.0076)$ & $-0.027^{* * *}$ & $(0.0076)$ \\
\hline Rural & $0.035^{* * *}$ & $(0.0100)$ & $0.035^{* * *}$ & $(0.0100)$ \\
\hline Full time & ref. & & ref. & \\
\hline Part time & -0.012 & $(0.010)$ & -0.012 & $(0.010)$ \\
\hline Temp not wrk & -0.0052 & $(0.020)$ & -0.0054 & $(0.020)$ \\
\hline Unemployed & $-0.32^{* * *}$ & $(0.016)$ & $-0.32^{* * *}$ & $(0.016)$ \\
\hline Retired & $0.067^{* * *}$ & $(0.013)$ & $0.067^{* * *}$ & $(0.013)$ \\
\hline In school & $0.046^{*}$ & $(0.019)$ & $0.046^{*}$ & $(0.019)$ \\
\hline Keeping house & $0.039^{* * *}$ & $(0.010)$ & $0.039^{* * *}$ & $(0.010)$ \\
\hline Other work status & $-0.13^{* * *}$ & $(0.022)$ & $-0.13^{* * *}$ & $(0.022)$ \\
\hline Democrat & ref. & & ref. & \\
\hline Republican & $0.062^{* * *}$ & $(0.0071)$ & $0.062^{* * *}$ & $(0.0071)$ \\
\hline Other party; no party & -0.0028 & $(0.0088)$ & -0.0023 & $(0.0088)$ \\
\hline State median income (logged) & -0.045 & $(0.057)$ & -0.045 & $(0.057)$ \\
\hline State percent foreign born & -0.15 & $(0.14)$ & -0.16 & $(0.14)$ \\
\hline State population density (logged) & $-0.020^{* *}$ & $(0.0068)$ & $-0.020^{* *}$ & $(0.0067)$ \\
\hline State percent black & $0.25^{* *}$ & $(0.078)$ & $0.25^{* *}$ & $(0.078)$ \\
\hline State poverty rate & $-0.0050^{*}$ & $(0.0020)$ & $-0.0051^{*}$ & $(0.0020)$ \\
\hline Constant & $2.81^{* * *}$ & $(0.63)$ & $2.82^{* * *}$ & $(0.63)$ \\
\hline $\operatorname{var}($ State $)$ & $0.0013^{* * *}$ & $*(0.00043)$ & $0.0013^{* * *}$ & $*(0.00043)$ \\
\hline $\operatorname{var}($ State-year) & $0.00089^{* *}$ & $* * 0.00033)$ & $0.00088^{* *}$ & $* * 0.00033)$ \\
\hline $\operatorname{var}($ Individual $)$ & $0.18^{* * *}$ & $(0.0049)$ & $0.18^{* * *}$ & $(0.0049)$ \\
\hline $\operatorname{var}($ Residual $)$ & $0.27^{* * *}$ & $(0.0045)$ & $0.27^{* * *}$ & $(0.0045)$ \\
\hline Observations & 51699 & & 51699 & \\
\hline
\end{tabular}

Standard errors in parentheses

${ }^{*} p<.05,{ }^{* *} p<.01,{ }^{* * *} p<.001$

Note: The middle income quintile (Q3) is the baseline category. 